\title{
Lidar-Radiometer Inversion Code (LIRIC) for the retrieval of vertical aerosol properties from combined lidar/radiometer data: development and distribution in EARLINET
}

\author{
Anatoli Chaikovsky ${ }^{1}$, Oleg Dubovik ${ }^{2}$, Brent Holben ${ }^{3}$, Andrey Bril ${ }^{1}$, Philippe Goloub $^{2}$, Didier Tanré2 \\ Gelsomina Pappalardo ${ }^{4}$, Ulla Wandinger ${ }^{5}$, Ludmila Chaikovskaya ${ }^{1}$, Sergey Denisov ${ }^{1}$, Jan Grudo ${ }^{1}$, Anton Lopatin ${ }^{1}$, \\ Yana Karol $^{1}$, Tatsiana Lapyonok ${ }^{2}$, Vassilis Amiridis ${ }^{6}$, Albert Ansmann ${ }^{5}$, Arnoud Apituley ${ }^{7}$, \\ Lucas Allados-Arboledas $^{8}$, Ioannis Binietoglou ${ }^{9}$, Antonella Boselli ${ }^{10,4}$, Giuseppe D'Amico ${ }^{4}$, Volker Freudenthaler ${ }^{11}$, \\ David Giles $^{3}$, María José Granados-Muñoz ${ }^{8}$, Panayotis Kokkalis ${ }^{6,12}$, Doina Nicolae ${ }^{9}$, Sergey Oshchepkov ${ }^{1}$, \\ Alex Papayannis ${ }^{12}$, Maria Rita Perrone ${ }^{13}$, Alexander Pietruczuk ${ }^{14}$, Francesc Rocadenbosch ${ }^{15}$, Michaël Sicard ${ }^{15}$, \\ Ilya Slutsker ${ }^{3}$, Camelia Talianu ${ }^{9}$, Ferdinando De Tomasi ${ }^{13}$, Alexandra Tsekeri ${ }^{6}$, Janet Wagner ${ }^{5}$, and Xuan Wang ${ }^{10}$ \\ ${ }^{1}$ Institute of Physics, NAS of Belarus, Minsk, 220072, Belarus \\ ${ }^{2}$ LOA, Universite de Lille, Lille, 59650, France \\ ${ }^{3}$ NASA Goddard Spaceflight Center, Greenbelt, MA 20771, USA \\ ${ }^{4}$ Consiglio Nazionale delle Ricerche - Istituto di Metodologie per l'Analisi Ambientale (CNR-IMAA), Potenza, 85050, Italy \\ ${ }^{5}$ Leibniz Institute for Tropospheric Research, Leipzig, 04318, Germany \\ ${ }^{6}$ Institute for Astronomy, Astrophysics, Space Applications and Remote Sensing, \\ National Observatory of Athens, Athens, 15236, Greece \\ ${ }^{7}$ KNMI - Royal Netherlands Meteorological Institute, De Bilt, 3731, the Netherlands \\ ${ }^{8}$ Andalusian Institute for Earth System Research (IISTA-CEAMA), University of Granada, Autonomous \\ Government of Andalusia, Granada, 18071, Spain \\ ${ }^{9}$ National Institute of R\&D for Optoelectronics, Magurele, 77125, Romania \\ ${ }^{10}$ Consorzio Nazionale Interuniversitario per le Scienze Fisiche della Materia, Naples, 80138, Italy \\ ${ }^{11}$ Ludwig-Maximilians Universität, Meteorological Institute, München, 80539, Germany \\ ${ }^{12}$ National Technical University of Athens, Department of Physics, Athens, 15780, Greece \\ ${ }^{13}$ Consorzio Nazionale Interuniversitario per le Scienze Fisiche della Materia (CNISM) and \\ Universita' del Salento, Lecce, 73100, Italy \\ ${ }^{14}$ Institute of Geophysics, Polish Academy of Sciences, Warsaw, 01-452, Poland \\ ${ }^{15}$ Remote Sensing Laboratory (RSLAB), Department of Signal Theory and Communications, Universitat Politècnica de \\ Catalunya (UPC)/Institute for Space Studies of Catalonia (IEEC), Barcelona, 08034, Spain
}

Correspondence to: Anatoli Chaikovsky (chaikov@dragon.bas-net.by)

Received: 19 October 2015 - Published in Atmos. Meas. Tech. Discuss.: 7 December 2015

Revised: 17 February 2016 - Accepted: 29 February 2016 - Published: 21 March 2016

\begin{abstract}
This paper presents a detailed description of LIRIC (LIdar-Radiometer Inversion Code) algorithm for simultaneous processing of coincident lidar and radiometric (sun photometric) observations for the retrieval of the aerosol concentration vertical profiles. As the lidar/radiometric input data we use measurements from European Aerosol Research Lidar Network (EARLINET) lidars and collocated
\end{abstract}

sun-photometers of Aerosol Robotic Network (AERONET). The LIRIC data processing provides sequential inversion of the combined lidar and radiometric data. The algorithm starts with the estimations of column-integrated aerosol parameters from radiometric measurements followed by the retrieval of height dependent concentrations of fine and coarse aerosols from lidar signals using integrated column characteristics of 
aerosol layer as a priori constraints. The use of polarized lidar observations allows us to discriminate between spherical and non-spherical particles of the coarse aerosol mode.

The LIRIC software package was implemented and tested at a number of EARLINET stations. Intercomparison of the LIRIC-based aerosol retrievals was performed for the observations by seven EARLINET lidars in Leipzig, Germany on 25 May 2009. We found close agreement between the aerosol parameters derived from different lidars that supports high robustness of the LIRIC algorithm. The sensitivity of the retrieval results to the possible reduction of the available observation data is also discussed.

\section{Introduction}

The aerosol impact on the radiation balance of the atmosphere is an important climate forcing factor. In addition, aerosol particles are among the unhealthiest air pollutants. This is made more severe by rapid propagation of pollutants in the atmosphere that expands local ecocatastrophes to a global scale. Therefore, the monitoring of the aerosol evolution and transport in the atmosphere is an obligatory prerequisite for predicting climatic and ecological changes.

Sun-radiometer and lidar networks contribute to aerosol remote sensing. The global Aerosol Robotic Network (AERONET) of ground-based sun-sky-scanning radiometers (e.g. Holben et al., 1998) provides reliable data on columnar aerosol properties from more than 200 globally distributed sites. The results of AERONET observations are the aerosol optical thickness (AOT) obtained from direct sun observations and additional microphysical and optical properties of aerosol particles (single scattering albedo, volume distribution of aerosol particles, complex refractive index, fraction of spherical particles, etc.) derived by the inversion of direct and scattered radiation measurements (Dubovik and King, 2000; Dubovik et al., 2002, 2004). The regional radiometer network SKYNET was established in the southeastern Asian regions (Takamura et al., 2004), and it employs its own equipment and processing procedure (Hashimoto et al., 2012).

The lidar measurements are used to provide information on the vertical variability of the aerosol characteristics. Currently, lidar networks, such as the European Aerosol Research Lidar Network (EARLINET) (Bösenberg et al., 2000; Pappalardo et al., 2014), the micro-pulse lidars network (MPL-Net) (Welton et al., 2002), the Asian dust network (AD-Net) (Murayama et al., 2001), the lidar network in former Soviet Union countries CIS-LiNet (Chaikovsky et al., 2005), the northeast American CREST Lidar Network (CLN) (Hoff et al., 2009), and the Latin America Lidar Network LALINET (Antuña et al., 2012), monitor aerosol vertical distributions in the atmosphere over vast regions of the Earth. The Global Atmosphere Watch (GAW) Aerosol Lidar Ob- servation Network (GALION), also known as the "network of networks" (e.g. Bösenberg and Hoff, 2007), was established under the aegis of GAW to coordinate lidar activity all over the world. The outcome of the lidar observations are presented in the lidar network databases as vertical profiles of aerosol backscatter and extinction coefficients.

Aerosol columnar properties from AERONET and aforementioned vertical profiles of aerosol parameters from lidar networks are complementary pieces of information characterizing aerosol properties. Nowadays, lidars and sun-skyscanning radiometers are among the basic tools in comprehensive experiments aimed at studying the transformation and transport of smoke (e.g. Lund Myhre et al., 2007; McKendry et al., 2011; Colarco et al., 2004), dust (e.g. Ansmann et al., 2009; McKendry et al., 2007; Müller et al., 2003; Papayannis et al., 2008), and volcanic ash (e.g. Ansmann et al., 2010, 2011, 2012; Papayannis et al., 2012; Gasteiger et al., 2011). A number of SKYNET sites (Takamura et al., 2004) and most of the EARLINET stations are equipped with lidar and radiometer instruments. Further enhancement of the aerosol characterization is expected from the synergy of colocated radiometer and lidar observations. Namely, the coordination of measurement procedures of the two systems and the derivation of aerosol parameters from combined measurements results in advanced characterization of the aerosol layer with a superior performance compared to the aerosol information that would have been obtained from independent processing of lidar and radiometer data.

The idea of combined lidar and radiometer sounding (LRS) for retrieving vertical distributions of aerosol characteristics was first proposed by Chaikovsky et al. (2002), and it gave rise to the development of the lidar-radiometer synergetic algorithms (e.g. Chaikovsky et al., 2004a, b). Later, in 2012 under the ACTRIS Research Infrastructure project within the European Union Seventh Framework Programme, the algorithm and software package, named LIRIC (LIdar-Radiometer Inversion Code), was developed for processing data of EARLINET measurements. LIRIC is based on processing co-located lidar and radiometer measurements by using a two-step sequential inversion. First, the radiometer data was processed according to the standard AERONET inversion algorithm. Then, first-step results are used as a priori constrains on aerosol properties for lidar data processing.

First application of LIRIC technique to the actual data processing was presented by Chaikovsky et al. (2004a). In that study, the technique was adapted to the EARLINETAERONET stations in Minsk (Belarus) and Belsk (Poland) (e.g. Chaikovsky et al., 2004c, 2010a; Pietruczuk and Chaikovsky, 2007). Results of the LRS observations were of interest for the study of long-range aerosol transport in the eastern European region (Kabashnikov et al., 2010; Chaikovsky et al., 2010b; Papayannis et al., 2014).

Another algorithm for data processing in combined lidarand-radiometer experiments exploits the decomposition of the AERONET column-integrated aerosol size distribution 
into log-normal modes and selection of some of these modes for the characterization of aerosol layers using measured lidar data (Cuesta et al., 2008).

The LRS technique for retrieving the aerosol concentration profiles from single-wavelength lidar measurements at the MPLNET (Micro-Pulse Lidar Network) stations collocated with the sun-sky radiometer sites of AERONET was developed by Ganguly et al., 2009a. Then this method was applied to processing of the combined AERONET and space CALIOP lidar data (Ganguly et al., 2009b).

Besides, the single-wavelength POLIPHON technique was developed as an alternative (e.g. Tesche et al., 2009; Ansmann et al., 2012). This technique retrieves particle volume concentration profiles of aerosol separately for fine and coarse fractions. The algorithm relies on the measured profiles of the particle linear depolarization ratio and lidar ratio, and it does not require the assumption of a specific particle shape. Columnar concentrations of aerosol modes retrieved by AERONET are used in POLIPHON as additional input data. The algorithm POLIPHON is designed for the data processing in lidar sounding of the aerosol layers with coarse non-spherical particles (dust, volcano ash).

In recent years, the LRS technique has been implemented within the advanced research network ACTRIS in the frame of EU 7th Framework Programme project. To date, a number of joint EARLINET/AERONET stations have implemented regular atmospheric observations using LIRIC for processing combined sun-radiometer and lidar-measured data (e.g. Chaikovsky et al., 2012; Papayannis et al., 2014; Tsekeri et al., 2013). The aerosol model and mathematical basis of the LIRIC algorithm became the prerequisite for further development of algorithms for simultaneous inversion of combined lidar-radiometer measurements, e.g. GARRLIC (Generalized Aerosol Retrieval from Radiometer and Lidar Combined data) (Lopatin et al., 2013) and the results of ground/satellite closure experiments (Dubovik et al., 2014). Note that LIRIC technique should not be regarded only as a basis for new algorithms (e.g. POLIPHON or GARRLIC). LIRIC might be superior to them for many aerosol scenarios: it allows one, for example, to distinguish between fine and coarse spherical fractions (unlike POLIPHON) or distinguish between spherical and non-spherical coarse particles (unlike GARRLIC). At the same time, a comprehensive description of the LIRIC algorithm has not been yet documented in detail.

This paper describes the basic physical and mathematical aspects of LIRIC algorithm with all necessary equations, thus filling up this gap. The appendices contain the details of the inversion scheme and can be useful for advanced users to modify and improve this code.

\section{The algorithm concept and structure}

The aerosol retrievals from combined lidar and radiometer measurements belong to a class of "ill-posed" inverse problems that, in particular, is characterized by non-unique and highly unstable solutions arising even under small measurement or simulation errors. In practice, the solution of the "illposed" problems requires the introduction a priori information (e.g. Turchin et al., 1971; Tikhonov and Arsenin, 1977; Twomey, 1977; Tarantola, 1987; Rodgers, 2000). LIRIC algorithm was designed on the basis of multi-term LSM (least square method) (Dubovik, 2004). This method was implemented in AERONET data processing (Dubovik and King, 2000) and then it was refined in the retrieval algorithms for the data processing of the combined optical measurements (e.g. Dubovik, 2004; Dubovik et al., 2011, 2014; Lopatin et al., 2013).

The inversion algorithm LIRIC can be divided into three key procedures (e.g. Tarantola, 1987): (i) parameterization of the object under study (i.e. development of the aerosol layer model); (ii) forward modelling, i.e. derivation of the equations that relate observed signals with specified parameters of the aerosol model; and (iii) inverse modelling or retrieval of the target parameters of the aerosol model that minimize discrepancies between the measured and the calculated input signals.

\subsection{Combined lidar/radiometer experiment and aerosol model}

The lidar/radiometer input data assumed to come from measurements of EARLINET lidars (e.g. Matthias et al., 2004; Freudenthaler et al., 2010) and spectral-scanning sunradiometers of AERONET (Holben et al., 1998). The majority of EARLINET lidar stations provides daytime measurements of elastic backscatter signals at three wavelengths $(355,532$, and $1064 \mathrm{~nm})$ and two cross/parallel-polarization components of the signal at a single wavelength. Additional information on aerosol parameters is expected to come from daytime Raman lidar measurements. (The current version of LIRIC algorithm is not designed for using Raman lidar data.)

Radiometric data includes results of direct-sun and almucantar (scanning) measurements (Holben et al., 1998; Dubovik and King, 2000). Direct-sun measurements are carried out in $15 \mathrm{~min}$ intervals. Almost-clear-sky measurements are required to obtain almucantar data, and approximately two to six successful measurements are made during the daytime under favourable meteorological conditions at EARLINET/AERONET stations. Under these circumstances, time synchronization of lidar and radiometric observations usually means nearly simultaneous measurements within the same $1 \mathrm{~h}$ interval.

These radiometric measurements enable the retrieval of the aerosol properties over the entire atmospheric column. Thus, except for volcanic events, the maximum lidar sounding height, $h_{\max }$, can be limited to the tropopause level because the stratospheric aerosol layer does not significantly contribute to columnar aerosol optical parameters. In contrast, aerosols in the lower troposphere are key contributors to the observed columnar characteristics. Consequently, it is 
desirable to perform the lidar sounding from the lowest possible altitude. Likewise, the contribution of the bottom layer (which is not observed by lidar) to the columnar optical parameters must be small enough to be modelled by a homogeneous layer with the same aerosol parameters as at the lowest level of lidar sounding. In practice, the lower sounding limit for most of the lidar measurements in EARLINET is about $200 \mathrm{~m}$ or more that can be too high especially for low boundary layers in winter seasons. It should be decreased in winter to compensate reduction of the boundary layer height. Therefore, lidar measurements in the lower layer have to be carried out by a second, complementary receiving system with smaller objective and larger field of view or by sounding the atmosphere along a slant trajectory.

The choice of the optical aerosol model is a key step of the retrieval algorithm. The optical model should be constructed following the principle of parsimony or "Occam's razor": the number of aerosol parameters has to be minimal but complete in order to provide unbiased retrieval from available measurements.

In this work, we use the AERONET model approach to characterize the aerosol layer of the atmosphere (Dubovik and King, 2000): aerosols are modelled by several modes with a certain aerosol particle size distribution, wherein each mode is a mixture of homogeneous spherical particles and randomly oriented spheroids (Dubovik et al., 2002, 2006). The distribution of the spheroid aspect ratio is fixed. The number of aerosol modes, $K$, depends on specification of the lidar data. If we use only total (scalar) backscatter lidar measurements, the aerosol model includes fine and coarse modes $(K=2)$. There is boundary size between fine and coarse fractions in the algorithm, which is determined as the value in $0.194-0.576 \mu \mathrm{m}$ range that corresponds to a minimum of the column particle volume size distribution, $\mathrm{d} V(r) / \mathrm{d} \ln r$. If measurements of cross and parallel co-polarized components are available, spherical and non-spherical particles of the coarse mode are considered as two different fractions $(K=3)$.

Thus, two sets of parameters characterize the aerosol layer.

1. The first is a number of columnar aerosol parameters retrieved from radiometer measurements (Dubovik and King, 2000; Dubovik et al., 2002, 2006). This set of parameters is formed by the following: (1) the total content of each aerosol mode, (i.e. columnar volume concentrations),

$$
\hat{C}_{k}^{V}=\int_{r_{\min , k}}^{r_{\text {max }, k}} \frac{\mathrm{d} V_{k}(r)}{\mathrm{d} \ln r} \mathrm{~d} \ln r,
$$

where $r_{\min , k}$ and $r_{\max , k}$ is the minimum and the maximum radius of the $k$ th aerosol mode $(k=$ $1, \ldots, K)$, respectively; (2) the particle volume size distributiond $V_{k}(r) / \mathrm{d} \ln r$ for each aerosol mode;
(3) complex refractive indices at the wavelength $\lambda$, $m(\lambda)=n(\lambda)+i \kappa(\lambda) ;$ (4) the "sphericity", $\zeta_{\text {sph }}$ (the ratio of spherical particle's volume to the total volume); (5) aerosol optical thickness (AOT) of the $k$ th aerosol mode, $\hat{E}_{k}\left(\lambda_{j}\right) ;(6)$ the single scattering albedo for the $k$ th aerosol mode, $\varpi_{k}(\lambda)$; (7) the elements of the backscattering matrix, $P_{x, x}^{k}\left(\lambda, 180^{\circ}\right)$; and (8) coefficients $\mathbf{a}_{k}$ and $\mathbf{b}_{k}$, which determine optical extinction and backscatter characteristics of aerosol particles for the $k$ aerosol mode (see Sect. 3.1). Parameters (1)-(4) are the independent "state" variables, whilst parameters (5)-(8) are derived from the state variables. Parameters $m(\lambda)$ and $\zeta_{\text {sph }}$ are assumed the same for particles of all sizes. Definitions and a detailed description of the columnar aerosol parameters are available at the AERONET information system; cloud screening and quality control algorithms were described by Holben et al. (2006).

2. The second set of parameters is represented by the height, $h$, distributions of particle volume concentrations (PVC) for each of aerosol mode, $c_{k}(h)$, which define the vertical variability of the aerosol features.

A lack of lidar data to resolve height-variation of aerosol microstructure motivates the assumption of altitudeindependent microphysical parameters of the aerosol modes.

\subsection{Algorithm's structure}

Two options of the retrieval procedure for the processing LRS data have been developed:

1. First one deals with sequential inversion of lidar and radiometer data. It is carried out by preliminary calculation of the column parameters defined in Sect. 2.1 from radiometric measurements by using the AERONET inversion algorithm (Dubovik and King, 2000), followed by subsequent inversion of the height distribution parameters by using lidar data with columnar characteristics of aerosol layer passed as a priori data (Chaikovsky et al., 2012);

2. Second option suggests simultaneous inversion approach for retrieving optimal parameters of the aerosol model by using a joint inversion procedure from combined lidar and radiometer data.

While the sequential algorithm could be considered as an unsophisticated inversion procedure to combine lidar and AERONET data, the parallel inversion method leads, in principle, to more effective estimation of aerosol parameters because it allows simultaneously retrieved columnar aerosol parameters to be specified in accordance with the additional lidar data. Currently, the simultaneous inversion algorithm for a two-component aerosol model is implemented in GARRLIC (Lopatin et al., 2013). Similar aerosol mode concentration profiles and residual discrepancies between measured 
and calculated input signals are obtained from both retrieval procedures when processing experimental data (Lopatin et al., 2013).

Advantages of the "simultaneous inversion approach" are expected for more involved measurements, such as in the unified algorithm GRASP (Generalized Retrieval of Aerosol and Surface Properties), which aimed at characterizing atmospheric properties from remote ground and satellite observations (Dubovik et al., 2014).

LIRIC algorithm described below was created on the base of the sequential inversion approach. Figure 1 shows the structure of the algorithm.

The algorithm is divided into several rather independent modules to provide flexibility of the software package. Module 1 (preprocessing of lidar data) creates a set of smoothed and normalized lidar signals, $L^{*}$, covariance matrix, $\boldsymbol{\Omega}_{L}$, and setting parameters (type of lidar measurement, sounding wavelength, geographical coordinates of lidar station and date of measurement, etc.) for modelling aerosol and molecular layers. Module 2 (recalculation of radiometer data) estimates columnar parameters of the aerosol model for lidar sounding wavelengths. Level 1.5 or Level 2.0 AERONET data are acceptable as input data in LIRIC. (These data are inputs to Module 2). Initial profiles of the aerosol-mode concentrations, $c_{k}^{0}(h)$, as well as molecular (Rayleigh) extinction, $\sigma_{r}(\lambda, h)$, and molecular backscatter coefficients, $\beta_{r}(\lambda, h)$, are generated by Module 3 (atmospheric model). Module 4 (forward model) calculates arrays of lidar signals, $L_{j}\left(c_{k}^{m-1}(h)\right)$, and columnar volume concentrations, $\hat{C}_{k}^{V, m-1}$, given aerosol concentration profiles, $c_{k}^{m-1}(h)$, in iterative inversion procedure, where " $m$ " stands for the $m$ th retrieval iteration and " $j$ " is the number of the receiving channel. Inversion parameters, constraints on the smoothness characteristics, and error signals for the sensitivity test are passed to the algorithm by Module 5 (inversion settings \& error modelling). The sensitivity test (see Sect. 6) was designed to estimate the response of the retrieval results to measurement errors and/or uncertainties of input data. Module 6 (numerical inversion) is responsible for fitting aerosolmode concentration profiles for the retrieved aerosol model, $c_{k}^{m-1}(h)$, given measured data and a priori information.

\section{Forward modelling of LRS experiment}

Range-corrected normalized lidar signals and columnaraerosol parameters retrieved from radiometer measurements are the input data to the LRS processing procedure (see Fig. 1). Below, we define a set of basic equations that are needed for the forward modelling of the measured quantities as well as to estimate the error-covariance matrix.

\subsection{Basic lidar equations}

The multichannel lidar carries out $J$ "different" lidar measurements $(j \in 1, \ldots J)$ that yields a set of lidar signal records, $P_{j}^{*}, j \in 1, \ldots J$. The term "different" means that different kinds of lidar measurements are performed, such as total intensity as well as cross- and parallel-polarized signal components at different wavelengths. Here we consider that each "different" lidar measurement is provided by a specific $j$-th channel. Parameter $J$ stands for the number of lidar channels irrespective of the actual implementation of the lidar system.

Range-corrected normalized lidar signals are calculated at the preprocessing stage of the inversion procedure (Module 1 in Fig. 1):

$L_{j}^{*}(h)=\frac{S_{j}^{*}\left(\lambda_{j}, h\right)}{S_{j}^{*}\left(\lambda, h_{\mathrm{ref}}\right)} \exp \left(-2 \tau_{r}\left(\lambda_{j}, h, h_{\mathrm{ref}}\right)\right)$,

where $S_{j}^{*}\left(\lambda_{j}, h\right)=P_{j}^{*}\left(\lambda_{j}, h\right) h^{2} ; \hat{S}_{j}^{*}\left(\lambda_{j}, h_{\text {ref }}\right)$ is the value of $S_{j}^{*}\left(\lambda_{j}, h\right)$ at the reference point, $h_{\text {ref }}$ is usually defined in the end of the sensing range, $\tau_{r}\left(\lambda_{j}, h, h_{\text {ref }}\right)$ is the molecular optical thickness related to the range of $\left(h, h_{\mathrm{ref}}\right), \lambda_{j}$ is the wavelength, and $h$ is the height. The set of lidar signals, $L_{j}^{*}(h)$, constitutes the input lidar vector, $\boldsymbol{L}^{*}$.

The lidar system provides measurements from the lowest to the highest altitude levels specified by $h_{\min }$ and $h_{\max }$, respectively. Currently, it is assumed that the radiometer is colocated at a height of $h_{0}<h_{\min }$, so columnar aerosol optical properties of the layer $h_{0}<h<h_{\min }$ are to be taken into consideration. If there is no information on the aerosol parameters in the surface layer, this layer is assumed to be homogeneous. Under this assumption, scattering parameters for the altitude range $h_{0}<h<h_{\min }$ of the lidar vector $\boldsymbol{L}^{*}$ are set equal to the values at $h_{\min }$.

The relationship between the measured lidar signals $L^{*}(\lambda)$ and the aerosol mode concentration, $c_{k}(h)$, can be written as follows:

$\boldsymbol{L}^{*}=L\left(\lambda, c_{k}(h), \mathbf{a}_{k}, \mathbf{b}_{k}\right)+\boldsymbol{\Delta}_{L}$,

where $\boldsymbol{\Delta}_{L}$ is the vector of measurement uncertainties. Here, an asterisk (*) denotes "measured" and no-asterisk denotes "model estimated".

Since function $L(.$.$) in Eq. (3) depends on the type of li-$ dar measurement, it is expedient to introduce special parameter, $p_{j} \in 1,2, \ldots, U$, that indicates the type of measurement associated to the $j$-channel of the lidar, and $U$ is a number of the types. In our case, $p_{j} \in 1,2,3$, indicates total intensity, cross-polarized, and parallel-polarized measurements, correspondingly.

The lidar functions, $L_{j, p_{j}}(\ldots)$, for the $p_{j}$-type measurements are defined by the following equations: 


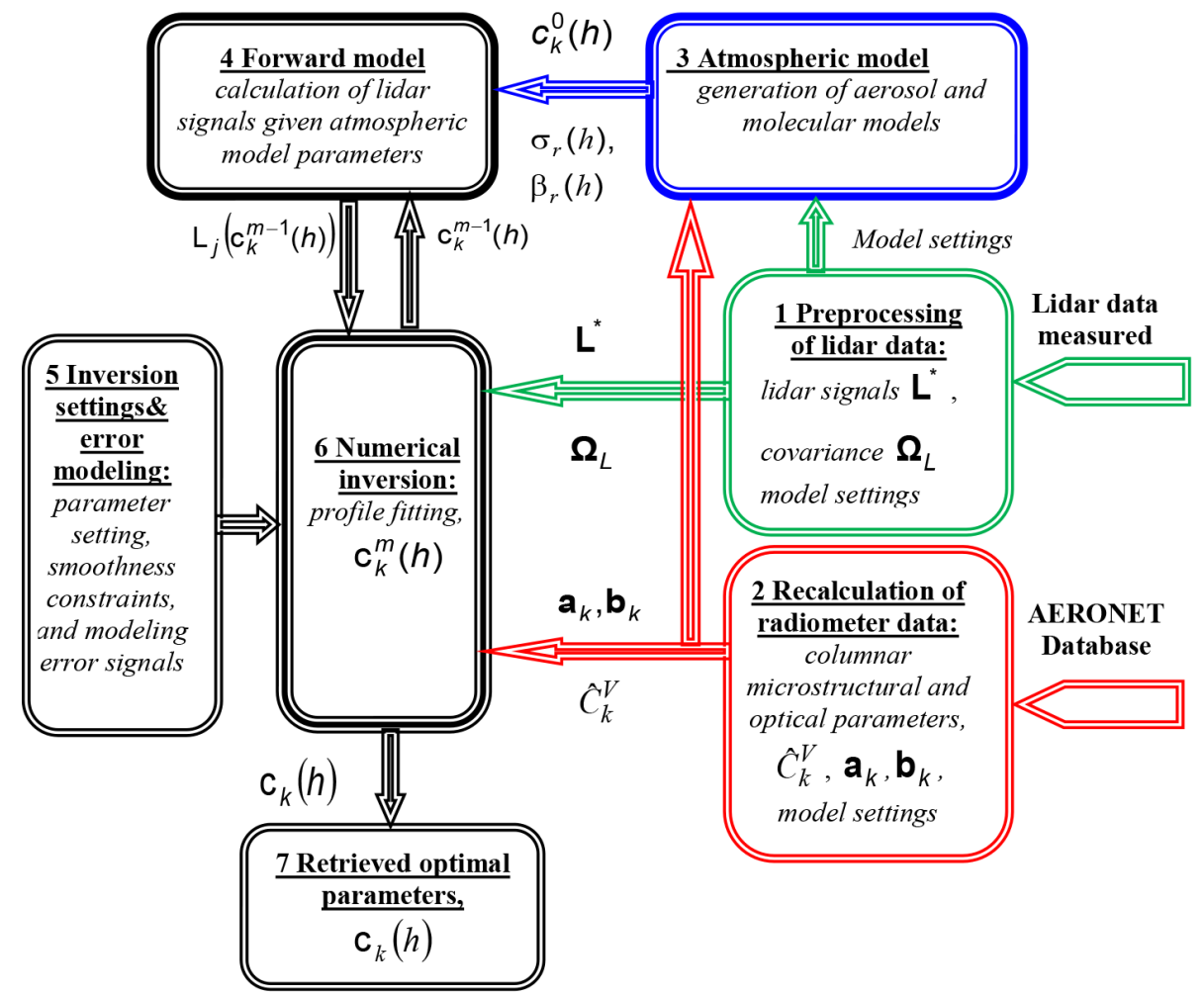

Figure 1. Flowchart of LIRIC algorithm. Details are in Sect. 2.2.

by the equation for the total backscatter signal,

$$
\begin{aligned}
L_{j, 1}\left(\lambda_{j}, h\right)= & \frac{\beta_{a, 1}\left(\lambda_{j}, h\right)+\beta_{r}\left(\lambda_{j}, h\right)}{R_{j, 1}\left(\lambda_{j}, h_{\mathrm{ref}}\right) \beta_{r}\left(\lambda_{j}, h_{\mathrm{ref}}\right)} \\
& \exp \left(-2 \int_{h_{\mathrm{ref}}} \sigma_{a}\left(\lambda_{j}, h\right) \mathrm{d} h\right),
\end{aligned}
$$

where

$$
R_{j, 1}\left(\lambda_{j}, h\right)=\frac{\beta_{a, 1}\left(\lambda_{j}, h\right)+\beta_{r}\left(\lambda_{j}, h\right)}{\beta_{r}\left(\lambda_{j}, h\right)} ;
$$

by the equation for the parallel-polarized signal component,

$$
\begin{aligned}
L_{j, 3}\left(\lambda_{j}, h\right)= & \frac{\beta_{a, 3}\left(\lambda_{j}, h\right)+\frac{1}{1+\chi} \beta_{r}\left(\lambda_{j}, h\right)}{\frac{1}{1+\chi} \beta_{r}\left(\lambda_{j}, h_{\mathrm{ref}}\right) R_{j, 3}\left(\lambda_{j}, h_{\mathrm{ref}}\right)} \\
& \exp \left(-2 \int_{h_{\mathrm{ref}}}^{h} \sigma_{a}\left(\lambda_{j}, h\right) \mathrm{d} h\right),
\end{aligned}
$$

where

$R_{j, 3}\left(\lambda_{j}, h\right)=\frac{\beta_{a, 3}\left(\lambda_{j}, h\right)+\frac{1}{1+\chi} \beta_{r}\left(\lambda_{j}, h\right)}{\frac{1}{1+\chi} \beta_{r}\left(\lambda_{j}, h\right)}$ and by the equation for the cross-polarized signal component,

$$
\begin{aligned}
& L_{j, 2}\left(\lambda_{j}, h\right)= \\
& \frac{\left(\beta_{a, 2}\left(\lambda_{j}, h\right)+\mu \beta_{a, 3}\left(\lambda_{j}, h\right)+\frac{\chi+\mu}{\chi+1} \beta_{r}\left(\lambda_{j}, h\right)\right)}{\frac{\chi+\mu}{\chi+1} \beta_{r}\left(\lambda_{j}, h\right) R^{\mathrm{eff}}\left(\lambda_{j}, h_{\mathrm{ref}}\right)} \\
& \exp \left(-2 \int_{h_{\mathrm{ref}}}^{h} \sigma_{a}\left(\lambda_{j}, h\right) \mathrm{d} h\right),
\end{aligned}
$$

where

$$
\begin{aligned}
R^{\mathrm{eff}}\left(\lambda_{j}, h\right)= & \left(\frac{\chi}{(\chi+\mu)} \frac{\beta_{a, 2}\left(\lambda_{j}, h\right)+\frac{\chi}{\chi+1} \beta_{, r}\left(\lambda_{j}, h\right)}{\frac{\chi}{\chi+1} \beta_{r}\left(\lambda_{j}, h\right)}\right. \\
& \left.+\frac{\mu}{(\chi+\mu)} \frac{\beta_{a, 3}\left(\lambda_{j}, h\right)+\frac{1}{1+\chi} \beta_{r}\left(\lambda_{j}, h\right)}{\frac{1}{1+\chi} \beta_{r}\left(\lambda_{j}, h\right)}\right) .
\end{aligned}
$$

In Eqs. (4)-(9), $\beta_{a, 1}, \beta_{a, 3}$, and $\beta_{a, 2}$ denote the aerosol backscatter coefficient and its parallel- and cross-polarized components, respectively; $\sigma_{a}\left(\lambda_{j}, h\right)$ is the aerosol extinction coefficient; $\chi\left(\lambda_{j}\right)=\frac{\beta_{r, 2}\left(\lambda_{j}\right)}{\beta_{r, 3}\left(\lambda_{j}\right)}$ is the ratio of cross- and parallel-polarized components of the molecular backscatter coefficient.

Different cross-talk factors contribute to the spurious signal in the cross-polarized receiving channel. These factors in- 
clude the residual of cross-polarized component of the laser beam, non-ideal adjustment of the polarization planes between transmitter/receiver channels and depolarization by optical elements. Equations (6) and (8) allow for these crosstalk effects in a similar manner to Chaikovskii (1990) and Biele et al. (2000). Thus, parameter $\mu$ in Eqs. (8)-(9) represents the leakage of the parallel component of the sounding beam into the cross-polarized lidar receiving channel. Parameter $\mu$ is an instrument characteristic that is assumed to be a known quantity; i.e. it is not updated by the retrieval procedure.

The aerosol extinction and backscatter coefficients in the Eqs. (3)-(9) are expressed as a function of the parameters of the following aerosol modes:

$$
\begin{aligned}
& \sigma_{a}\left(\lambda_{j}, h\right)=\sum_{k} c_{k}(h) a_{k}\left(\lambda_{j}\right), \\
& \beta_{a, 1}\left(\lambda_{j}, h\right)=\sum_{k} c_{k}(h) b_{k, 1}\left(\lambda_{j}\right), \\
& \beta_{a, 2}\left(\lambda_{j}, h\right)=\sum_{k} c_{k}(h) b_{k, 2}\left(\lambda_{j}\right),
\end{aligned}
$$

and

$\beta_{a, 3}\left(\lambda_{j}, h\right)=\sum_{k} c_{k}(h) b_{k, 3}\left(\lambda_{j}\right)$.

The coefficients $a_{k}\left(\lambda_{j}\right)$ and $b_{k, x}\left(\lambda_{j}\right)$, pointed out in Sect. 2.1, are determined by columnar optical parameters of aerosol modes:

$$
\begin{aligned}
a_{k}\left(\lambda_{j}\right)= & \frac{\hat{E}_{k}\left(\lambda_{j}\right)}{\hat{C}_{k}^{V}}, \\
b_{k, 1}\left(\lambda_{j}\right)= & \frac{1}{4 \pi} \varpi_{k}\left(\lambda_{j}\right) a_{k}\left(\lambda_{j}\right) P_{1,1}^{k}\left(\lambda_{j}, 180^{\circ}\right), \\
b_{k, 3}\left(\lambda_{j}\right)= & \frac{1}{4 \pi} \varpi_{k}\left(\lambda_{j}\right) a_{k}\left(\lambda_{j}\right) \\
& \frac{P_{1,1}^{k}\left(\lambda_{j}, 180^{\circ}\right)+P_{2,2}^{k}\left(\lambda_{j}, 180^{\circ}\right)}{2}, \\
b_{k, 2}\left(\lambda_{j}\right)= & \frac{1}{4 \pi} \varpi_{k}\left(\lambda_{j}\right) a_{k}\left(\lambda_{j}\right) \\
& \frac{P_{1,1}^{k}\left(\lambda_{j}, 180^{\circ}\right)-P_{2,2}^{k}\left(\lambda_{j}, 180^{\circ}\right)}{2},
\end{aligned}
$$

where $\hat{E}_{k}$ is aerosol optical thickness for the $k$ th aerosol mode, $\varpi_{k}(\lambda)$ is the single scattering albedo for the $k$ th aerosol mode, and $P_{x, x}^{k}\left(\lambda, 180^{\circ}\right)$ are the elements of the backscattering matrix.

\subsection{Forward model of radiometer data}

In accordance with the multi-term LSM approach (Dubovik, 2004), the columnar concentrations of aerosol modes, $\hat{C}_{k}^{V}$, obtained from radiometer measurements are formally considered in LIRIC as a result of additional independent measurements.

The equation for the vector, $\hat{\boldsymbol{C}}^{* V}$, which is defined as the "measured" columnar volume concentrations of the aerosol modes given vector of aerosol modes concentration, $c\left(h_{i}\right)$, $i \in 1, \ldots I$, can be written in the following form:

$\hat{\boldsymbol{C}}^{* V}=\mathbf{H c}+\boldsymbol{\Delta}_{V}$,

where $\mathbf{H}$ is convolution matrix for summing the heightresolved concentration over the column; $\boldsymbol{\Delta}_{V}$ is the vector of $\hat{\boldsymbol{C}}^{* V}$ uncertainties.

The $k$-th component of the vector $\hat{\boldsymbol{C}}^{* V}$ is defined by the following equation:

$C_{k}^{* V}\left(c_{k}\left(h_{i}\right)\right)=\sum_{i=1}^{I} c_{k}\left(h_{i}\right) \Delta h_{i}+\Delta_{V, k}$.

The structure of the vectors $\hat{\boldsymbol{C}}^{* V}, \boldsymbol{c}$, and matrix $\mathbf{H}$ is considered in Appendix C.

\section{Numerical inversion}

Statistical regularization technique (e.g. Turchin et al., 1971; Tarantola, 1987; Rodgers, 2000) considers errors, $\boldsymbol{\Delta}_{L}$ and $\boldsymbol{\Delta}_{V}$, in Eqs. (3) and (18) as random variables. Under the additional assumption that errors have independent normal distributions, the multidimensional conditional probability density function (PDF) (or "likelihood function") is defined by Chaikovsky et al. (2004a)

$$
\begin{aligned}
& F\left(\boldsymbol{L}^{*}, \hat{\boldsymbol{C}}^{* V} \mid \boldsymbol{c}\right) \sim \exp \left[\left(-\frac{1}{2}\left(\left(\boldsymbol{L}^{*}-\boldsymbol{L}(\boldsymbol{c})\right)^{T} \boldsymbol{\Omega}_{L}^{-1}\right.\right.\right. \\
& \left(\boldsymbol{L}^{*}-\boldsymbol{L}(\boldsymbol{c})\right)+\left(\hat{\boldsymbol{C}}^{* V}-\mathbf{H c}\right)^{T} \\
& \left.\left.\left.\boldsymbol{\Omega}_{V}^{-1}\left(\hat{\boldsymbol{C}}^{* V}-\mathbf{H c}\right)\right)\right)\right]
\end{aligned}
$$

Here, $F\left(\boldsymbol{L}^{*}, \hat{\boldsymbol{C}}^{* V} \mid \boldsymbol{c}\right)$ is the PDF of measurement vectors $\boldsymbol{L}^{*}$ and $\hat{\boldsymbol{C}}^{* V}, \boldsymbol{L}(\boldsymbol{c})$ is the vector function in Eq. (3), $\mathbf{H}$ is the matrix in Eq. (18), $c$ is the target retrieval vector of aerosol modes concentration, and $\boldsymbol{\Omega}_{L}$ and $\boldsymbol{\Omega}_{V}$ are the covariance matrices of error vectors $\boldsymbol{\Delta}_{L}$ and $\boldsymbol{\Delta}_{V}$, respectively.

An extensively used tool for the regularization of an "illposed" problem is the application of a priori constraint on the smoothness of retrieved characteristics. LIRIC restricts the norms of the second differences of functions $c_{k}\left(h_{i}\right)$. Following the statistical regularization approach (Turchin et al., 1971) we included a priori probability function,

$F_{\text {apr }}(\boldsymbol{c}) \sim \exp \left(-\frac{1}{2}\left(\boldsymbol{c}^{T} \boldsymbol{\Omega}_{S} \boldsymbol{c}\right)\right)$

into the retrieval procedure as the additional constraint. Here, $\boldsymbol{\Omega}_{S}=\mathbf{S}_{2}^{T} \mathbf{Q}_{2}^{-1} \mathbf{S}_{2}$ is the smoothing matrix, $\mathbf{S}_{2}$ is the matrix of 
the second-order differences, and $\mathbf{Q}_{2}$ is diagonal weighting matrix (Twomey, 1977; Dubovik et al., 2011).

The Bayes' strategy (Turchin et al., 1971; Tarantola, 1987; Rodgers, 2000) for solving an "ill-posed" problem combined with multi-term LSM technique (Dubovik, 2004; Dubovik et al., 2011) defines the solution $\hat{\boldsymbol{c}}$ in accordance with the maximum a posteriori rule

$\hat{\boldsymbol{c}}=\arg \min _{\boldsymbol{c}}\{\Psi(\boldsymbol{c})\}$,

where the objective or cost function, $\Psi(\boldsymbol{c})$, has the following multi-term representation (Dubovik, 2004; Dubovik et al., 2011)

$$
\begin{aligned}
\Psi(\boldsymbol{c})= & \left(\boldsymbol{L}^{*}-\boldsymbol{L}(\boldsymbol{c})\right)^{T} \boldsymbol{\Omega}_{L}^{-1}\left(\boldsymbol{L}^{*}-\boldsymbol{L}(\boldsymbol{c})\right) \\
& +\left(\hat{\boldsymbol{C}}^{* V}-\mathbf{H} \mathbf{c}\right)^{T} \boldsymbol{\Omega}_{V}^{-1}\left(\hat{\boldsymbol{C}}^{* V}-\mathbf{H c}\right) \\
& +\left(\boldsymbol{c}^{T} \mathbf{S}_{2}^{T} \mathbf{Q}_{2}^{-1} \mathbf{S}_{2} \boldsymbol{c}\right)
\end{aligned}
$$

We assume that the errors $\boldsymbol{\Delta}_{L}$ in Eq. (3) and $\boldsymbol{\Delta}_{V}$ in Eq. (18) are uncorrelated. In this case, the non-zero diagonal elements of the covariance matrices $\boldsymbol{\Omega}_{L}$ and $\boldsymbol{\Omega}_{V}$ are the variances of the elements of the vectors $\boldsymbol{\Delta}_{L}$ and $\boldsymbol{\Delta}_{V}$, respectively.

Since the minimization procedure does not prescribe a residual value for $\Psi(\boldsymbol{c})$, it is convenient to reformulate weight matrices as follows (Dubovik, 2004):

$\breve{\boldsymbol{\Omega}}_{L}=\frac{1}{\varepsilon_{L}^{2}} \boldsymbol{\Omega}_{L} ; \quad \breve{\boldsymbol{\Omega}}_{V}=\frac{1}{\varepsilon_{V}^{2}} \boldsymbol{\Omega}_{V} ; \quad \breve{\boldsymbol{\Omega}}_{S}=\frac{1}{\varepsilon_{S}^{2}} \boldsymbol{\Omega}_{S}$,

where $\varepsilon_{L}^{2}, \varepsilon_{W}^{2}$, and $\varepsilon_{S}^{2}$ are the first elements of the corresponding covariance matrices.

After substitution of the covariance matrices expressed through the weight matrices into Eq. (22) and multiplication it by $\varepsilon_{L}^{2}$, the $\Psi(\boldsymbol{c})$ takes the form of the sum of three components:

$\breve{\Psi}\left(\boldsymbol{L}^{*}, \hat{\boldsymbol{C}}_{V}, \boldsymbol{c}\right)=\breve{\Psi}_{L}\left(\boldsymbol{L}^{*}, \boldsymbol{c}\right)+\gamma_{V} \breve{\Psi}_{V}\left(\hat{\boldsymbol{C}}^{* V}, \boldsymbol{c}\right)+\gamma_{S} \breve{\Psi}_{S}(\boldsymbol{c})$,

where

$\breve{\Psi}_{L}\left(\boldsymbol{L}^{*}, \boldsymbol{c}\right)=\left(\boldsymbol{L}^{*}-\boldsymbol{L}(\boldsymbol{c})\right)^{T} \breve{\boldsymbol{\Omega}}_{L}^{-1}\left(\boldsymbol{L}^{*}-\boldsymbol{L}(\boldsymbol{c})\right)$,

is related to "lidar-measured" data, Eq. (3),

$\breve{\Psi}_{V}\left(\hat{\boldsymbol{C}}^{* V}, \boldsymbol{c}\right)=\left(\hat{\boldsymbol{C}}^{* V}-\mathbf{H c}\right)^{T} \breve{\boldsymbol{\Omega}}_{V}^{-1}\left(\hat{\boldsymbol{C}}^{* V}-\mathbf{H c}\right)$,

is related to radiometer-measured data, Eq. (18),

$\breve{\Psi}_{S}(c)=\left(c^{\mathbf{T}} \mathbf{S}^{\mathbf{T}} \breve{Q}_{2}^{-1} \mathbf{S c}\right)$,

is related to a priori information, Eq. (21),

$\gamma_{V}=\frac{\varepsilon_{L}^{2}}{\varepsilon_{V}^{2}} \quad ; \quad \gamma_{S}=\frac{\varepsilon_{L}^{2}}{\varepsilon_{2}^{2}}$.
The coefficients $\gamma_{V}$ and $\gamma_{S}$ are so-called Lagrange multipliers that determine the weight of different contributors from each source of information (i.e. "measurements" and "apriori" contribution) to the retrieval solution relative to the contribution of the first data source (since $\gamma_{L}=1$ ). Equations (22) and (24) are equivalent; however, Eq. (24) is more convenient for the analysis of the relative contribution from different data source.

If $\gamma_{V}, \gamma_{S} \rightarrow 0$, we return to a non-regularized solution for vector $c$ that is based solely on measured lidar data with the minimum discrepancy between measured and calculated input signals. This solution, however, could be nonphysical, multivalued, and unstable. The possible solution space should be restricted by increasing the Lagrange multipliers despite the fact that it results in increasing discrepancy between measured and model signal. The algorithms to determine the Lagrange multipliers by finding a reasonable compromise between the solution quality and the closeness of the measured and model signals are described in Hansen (2001), Vogel (2002), and Doicu et al. (2010). The set of Lagrange multipliers is provided to LIRIC's users along with software package. However, we do not consider this set as the ultimate one, and we allow it to be modified to meet user's specifications.

The final step of the retrieval procedure is calculation of the concentration profiles $c_{k}\left(h_{i}\right)$ for each aerosol mode. Initial approximations $c_{k}^{0}\left(h_{i}\right)$ are set and stepwise improved to provide the minimum of the objective function (Eq. 25). Increments are calculated by means of the LevenbergMarquardt method (Levenberg, 1944; Marquardt, 1963).

The analytical expressions of the terms of Eq. (25), the covariance matrices, and the details of the inversion procedure are described in Appendices A, B, and C.

\section{Program package for processing combined lidar and radiometer data}

Figure 2 shows the structure of the software package that implements the LIRIC algorithm. A set of specific programs are joined in three sub-packages.

The sub-package LiOpt implements module (2) of the LIRIC algorithm (Fig. 1), which provides preprocessing of the AERONET retrieval products. Program AERLID recalculates the columnar optical characteristics for the lidar sounding wavelengths, including the elements of the scattering matrices for the spherical and non-spherical particles as well as for fine and coarse aerosol modes. Then, this code transfers data to the radiometer database.

The preprocessing of lidar data is carried out by the SignalSuite sub-package. It contains several programs. Among them are the following:

- ULIS - an operational program that provides measurement procedures and record of raw lidar data to $\mathrm{Mi}$ crosoft ACCESS database; 


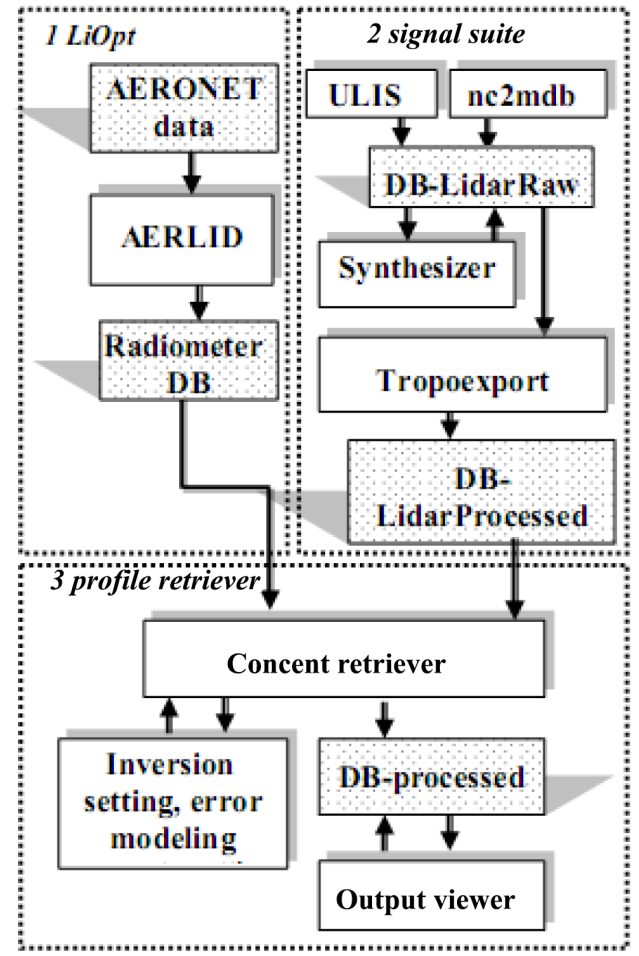

Figure 2. Flowchart of the program package.

- nc2mdb - a program to convert EARLINET standard raw-lidar nc (network common data form) files into mdb (database file used by Microsoft Access) files to process by LIRIC;

- Synthesizer - a program to average the series of lidar signals, converts the profiles to the optimal altitude scale and, then, "glues" signals (i.e. synthesizes single signal) for the upper and lower troposphere, which were measured with different receiving systems, as well as provides the "dead-time" correction, i.e. the correction for the finite time resolution of the photo-counting system;

- Tropoexport - a program to calculate a normalized smoothed lidar signal and its variance, and generates molecular and aerosol atmospheric models; this program aims at implementing modules 2 and 3 of the algorithm.

Finally, the main sub-package "ProfileRetriever" implements the LIRIC inversion procedure. The program "ConcentRetriever" retrieves profiles $c_{V}^{k, m}(h)$ of the aerosol mode concentrations and writes data down to ACCESS database, DBprocessed. The module "inversion setting \& errors modelling" generates a set of noise-corrupted input data files by adding white noise and amplitude distortions to the initial lidar signals and perturbing aerosol model parameters retrieved from radiometer measurements in order to provide the error sensitivity analysis. The user can upgrade default instrumental noise parameters to meet real measurement conditions and technical features of the lidar system; the accuracy of columnar aerosol parameters retrieved from the radiometer measurements (Dubovik and King, 2000; Dubovik et al., 2000) is also taken into account in setting parameters of the module. The program "OutputViewer" allows viewing the output data and their conversion from mdb-files into other formats.

\section{Verification of operability and sensitivity tests}

The LRS technique uses the aerosol model that was initially developed in AERONET to describe column-averaged aerosol properties and generalized it to the case of the height-resolved aerosol concentrations. This model assumes that aerosol consists of fine and coarse modes and that both are mixtures of spherical particles and randomly oriented homogeneous spheroids. The advanced T-matrix code (Mishchenko al., 2000, 2002) provides computation of scattering matrices of the aerosol particles. Thus, any optical characteristic of the aerosol layer can be calculated using data of the LRS experiment.

The applicability analysis of the AERONET spheroid model to aerosol particles is beyond the scope of this paper. We only note that this model was validated by the comparison of calculated optical parameters and laboratory measurements of light scattering matrices for mineral dust particles (Volten et al., 2001). Incorporation of the spheroid model into AERONET operational retrieval code has significantly improved AERONET products when evaluating parameters of coarse non-spherical particles (Cattrall et al., 2005; Dubovik et al., 2006). This model has also been incorporated when processing data from ground-based polarimetric measurements (e.g. Li et al., 2009), lidar sounding data (e.g. Veselovskii et al., 2010; David et al., 2013; Müller et al., 2013), and satellite-base observations (e.g. Levy et al., 2007a, b; Dubovik et al., 2011; Schuster et al., 2012).

\subsection{Verification of LIRIC program package: EARLI09 intercomparison experiment}

EARLI09 intercomparison experiment was held in May 2009 at Leibniz Institute for Tropospheric Research in Leipzig, Germany (Wandinger et al., 2015). This campaign provided an excellent opportunity to validate the LRS technique for network measurements. The results of the LIRIC data processing for simultaneous measurements by seven lidars of different scientific teams on 25 May 2009 in Leipzig were compared.

Total optical depth distribution (Fig. 3a) and backtrajectory analysis (Fig. 3b) indicates that LRS measurements were carried out during the Saharan dust event in the Leipzig region and the dust was transported in the layer above $2 \mathrm{~km}$. 

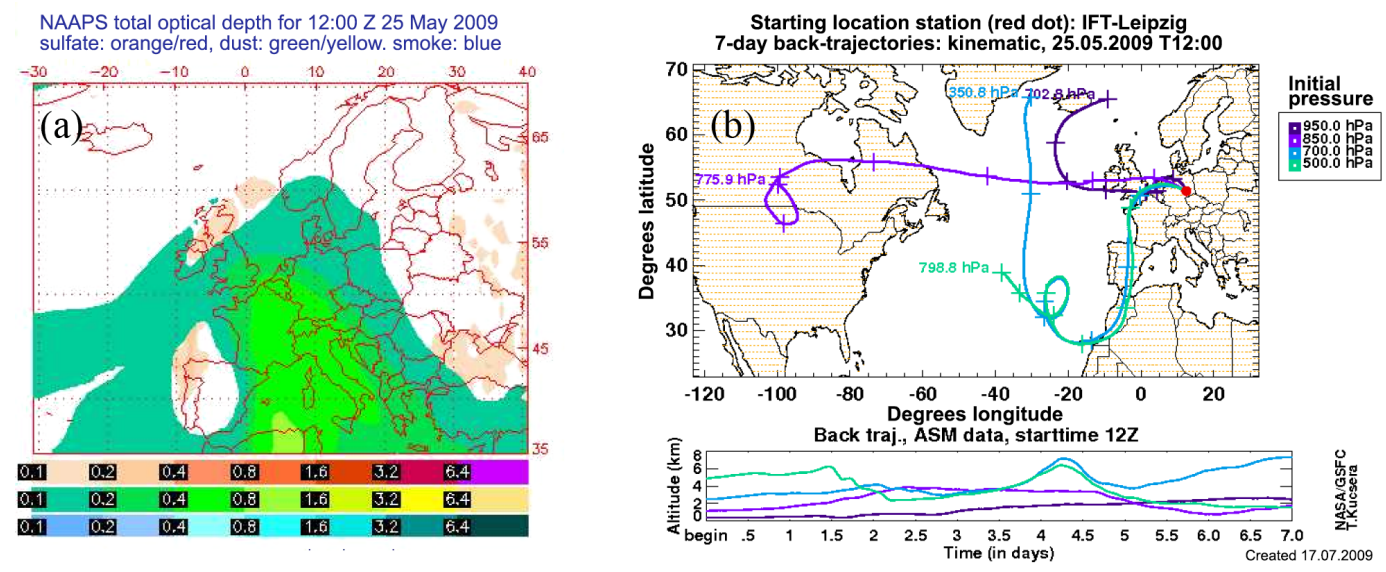

Figure 3. EARLI09 intercomparison experiment: (a) NAAPS Total Optical Depth forecast, 25 May 2009 at 12:00 UTC; (b) 7-day back trajectories ending over Leipzig, Germany at 12:00 UTC on 25 May 2009.

(a)

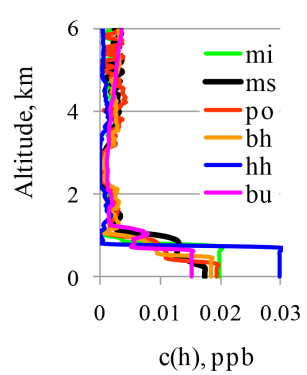

(d)

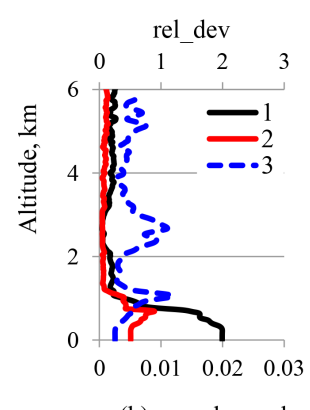

$\mathrm{c}(\mathrm{h})$, rms dev, ppb (b)

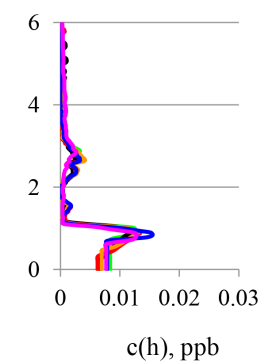

(e)

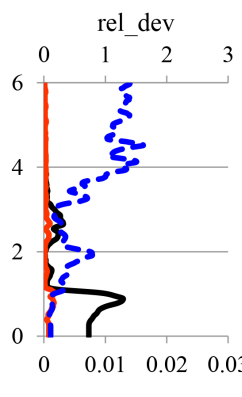

$\mathrm{c}(\mathrm{h}), \mathrm{rms}$ dev, ppb (c)

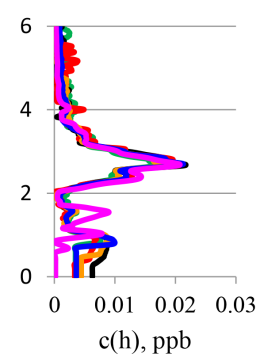

(f)

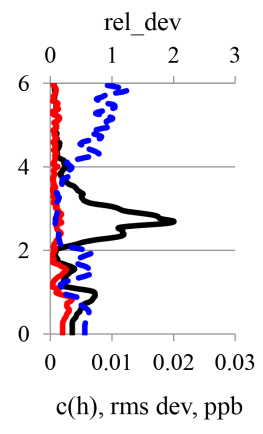

Figure 4. Particle volume concentrations (PVC) profiles, $c_{k}(h)$, and estimated deviations retrieved from data of EARLI09 intercomparison campaign, 10:20-11:40 UTC, 25 May 2009, Leipzig, Germany, measured in Leipzig by six EARLINET lidars: mi - Minsk, ms - München, po - Potenza, bh - Bilthoven, hh - Hamburg, bu Bucharest; (a, d) - fine, (b, e) - coarse spherical; (c, f) - coarse nonspherical; 1 - average PVC profile, 2 - rms-deviation (rms_dev), 3 - relative deviation (rel_dev). Measured data from four lidar channels (355, 532-parallel, 532-cross, $1064 \mathrm{~nm}$ ) and three-mode aerosol model were used.

Figures 4 and 5 show PVC profiles, $c_{k}(h)$, retrieved from lidar data of the different EARLINET teams combined with

(a)

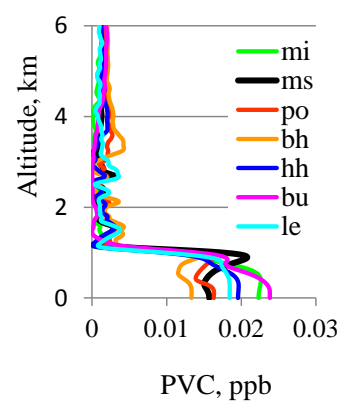

(c)

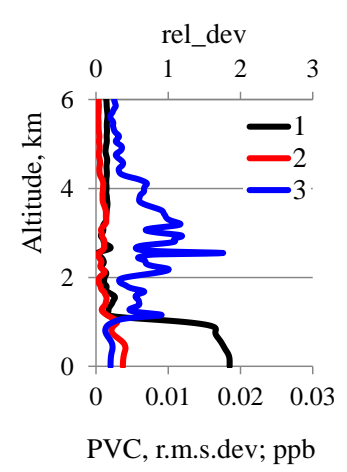

(b)

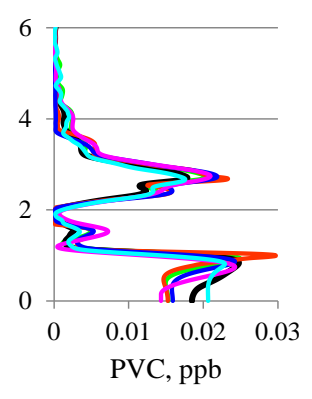

(d)

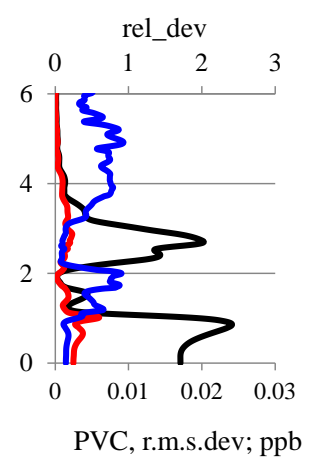

Figure 5. Identical to Fig. 4 except for data from three lidar channels $(355,532$ - intensity/parallel polarized component, and $1064 \mathrm{~nm}$ ) and two mode aerosol model were used. Label "le" stands for lidar "PollyXT" of TROPOS, Leipzig: $(\mathbf{a}, \mathbf{c})$ - fine, $(\mathbf{b}, \mathbf{d})-$ coarse spherical aerosol mode.

the same AERONET information, as well as their root mean square deviations and relative deviations for the two types of input data set, namely, with and without depolarization measurements. 
It is evident from Figs. $4 \mathrm{a}-\mathrm{c}$ and $5 \mathrm{a}-\mathrm{b}$ that $c_{k}(h)$ profiles have similar structure over the troposphere except for the lower layer. The relative deviations increase mainly when values of the aerosol concentration become negligible. The discrepancies are also possible in the near-surface atmospheric layer due to overlap effect (e.g. for the Hamburg lidar system, Fig. 4a).

We explain the discrepancy between $c_{k}(h)$ profiles in the near-surface atmosphere by the uncertainty in geometrical overlap factors and the differences in lower-boundary heights of the considered lidar systems. Also some differences in the retrieved concentration profiles $c_{k}(h)$ are due to measurement errors and uncertainties in aerosol modelling.

The potential errors in the PVC profiles for the specific combined lidar/radiometer experiment were estimated by using the Errors modelling module of the LIRIC package (Fig. 2). Figures 6 and 7 illustrate the sensitivity of the retrieved aerosol concentration profiles to the errors of the lidar measurements. The original lidar signals were taken as they measured by München lidar (curves 4 in Fig. 6) and have been perturbed by adding white noise with different rootmean-square deviations (rms-deviations), $\alpha_{j}$, and have been distorted by multiplying them by the coefficient,

$k_{j}\left(h_{i}\right)=1+\frac{\Delta_{j}}{100} \frac{h_{\mathrm{ref}}-h_{i}}{h_{\mathrm{ref}}}$,

where percentage parameter $\Delta_{j}$ determines the amount of non-linearity.

In response, the program module generated 12 disturbed lidar signal sets that allowed us to estimate the impact of measurement errors. As an illustration, Figs. 6 and 7 simulate higher errors than typical sets in most EARLINET lidars. Four realizations of the disturbed signals are shown in Fig. 6. Coefficient $k_{j}\left(h_{i}\right)$ increases/decreases from referent to start point that results in divergence of the lidar signals in Fig. 6.

PVC profiles, $c_{k}(h)$, corresponding to the lidar signals in Fig. 6 and their rms-deviations calculated for full ensembles of input data are shown in Fig. 7. Changes in the PVC profiles of the dominant coarse non-spherical mode are shown by the Fig. 7 to be minor (Fig. 7c). Although profiles $c_{k}(h)$ of fine and coarse spherical particles (Fig. 7a and b) are not very stable, they qualitatively retain similarity with the initial distributions.

Figure 8 illustrates the effect of uncertainties in columnar aerosol parameters retrieved from radiometer data. Variations of the columnar aerosol characteristics lead to changes in coefficients $a$ and $b$ of lidar-related Eqs. (14)-(17) (Sect. 3.1). Statistical characteristics of aerosol concentration profiles retrieved with relative deviation of the parameter $\vartheta_{k, p}^{j}$ (effective lidar ratio of the aerosol fraction, see Appendix B) in the range $\pm 20 \%$ (the full range) are presented in Fig. 8. Relative deviation of aerosol concentration profile becomes significant only for small values of the concentration. (a)

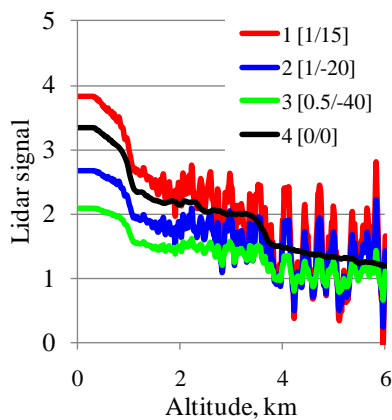

(c)

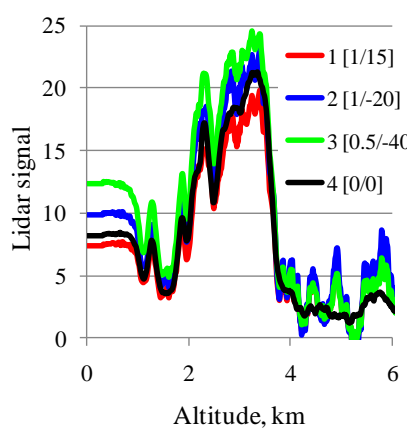

(b)

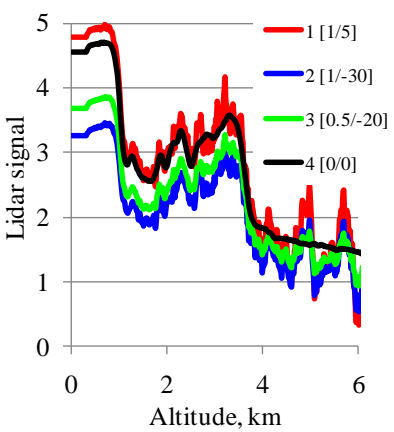

(d)

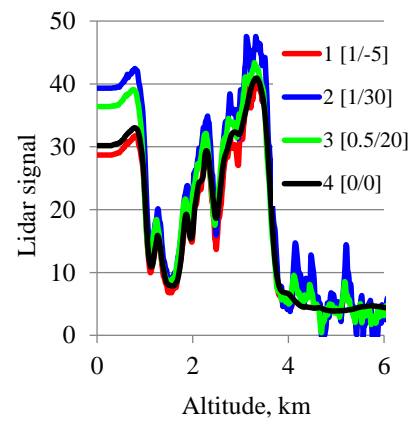

Figure 6. Range-corrected normalized lidar signals, $\boldsymbol{L}^{*}$, corrupted with noise and amplitude distortions. Original data are provided by the München lidar team in the frame of EARLI09 intercomparison campaign, 14:30-15:30 UTC, 25 May 2009, Leipzig, Germany: (a) $-355 \mathrm{~nm}$, (b) $1064 \mathrm{~nm}$, (c) $-532 \mathrm{~nm}$, parallel polarized, (d) $532 \mathrm{~nm}$, cross polarized; 4 - original signal, 1-3 - corrupted signals. In square brackets distortion parameters $\alpha_{j} / \Delta_{j}$ are given.

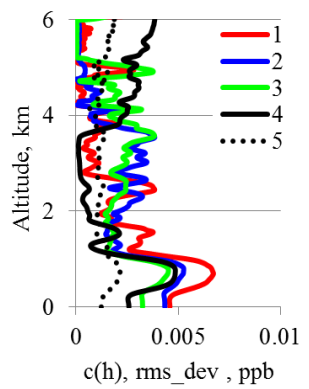

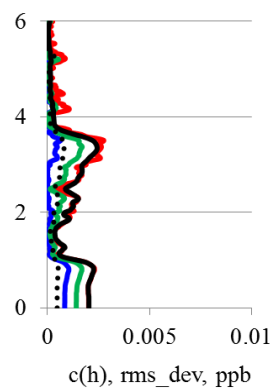

(c)

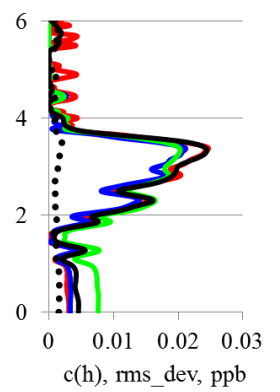

Figure 7. PVC profiles, $c_{k}(h)$, and their rms-deviations retrieved in response to disturbed data from of the München lidar, EARLI09 intercomparison campaign, 14:30-15:30 UTC, 25 May 2009, Leipzig, Germany: (a) - fine, (b) - coarse spherical, (c) - coarse nonspherical modes; 4 - for the original signal, 1-3 - for disturbed signals; 5 -rms-deviation.

\subsection{Dependence of retrieved aerosol concentration profiles on the content of the input data set}

Three types of data set related to different sources of information compose the LIRIC input data-file: three or four 


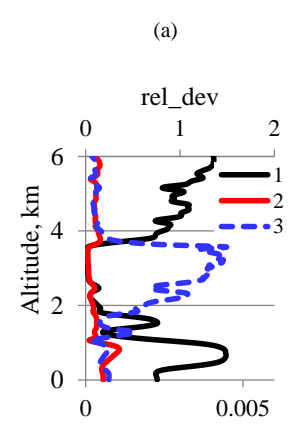

c(h), rms_dev, ppb
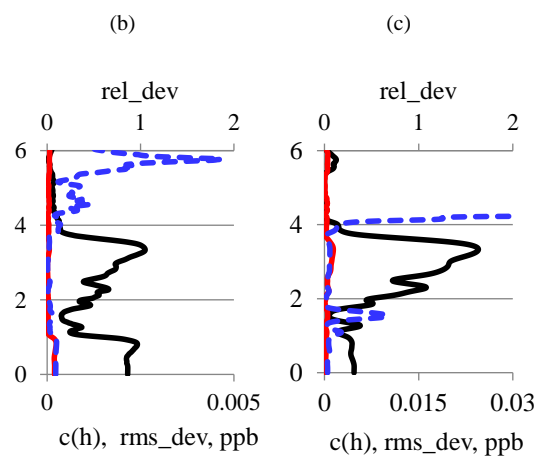

Figure 8. Variations of PVC profiles, $c_{k}(h)$, retrieved with $20 \%$ uncertainties in the aerosol lidar ratios; data of München lidar, EARLI09 intercomparison campaign, 14:30-15:30 UTC, 25 May 2009, Leipzig, Germany are used; (a) fine, (b) coarse spherical, (c) coarse non-spherical modes; 1 - average value, 2 - rmsdeviation, 3 - relative deviation.

measured lidar signals, column-aerosol parameters from radiometer measurements, and a priori smoothness constraints. Two- or three-mode aerosol models are used according to the type of the measured lidar signals. Formally, we deal with redundant input information and, hence, for the accepted aerosol model, the number of input data set can be decreased. Consequently, the significance of the different information components in retrieval procedure is of interest as well as variations of the retrieved profiles, $c_{k}(h)$, in the absence of some input data

As pointed out in Sect. 4, the objective functions of LIRIC regularization algorithm (Eq. 22), consists of a set of terms that implement contribution of different types of input data into the retrieval process. Setting the variance of the specific kind of measurement to a large value implies neglecting the correspondent term in the objective function (Eq. 22) and the elimination of this part of the input data in estimation of the final aerosol parameters. Program package implements this option and makes allowing one to analyze the contribution of different measured data in the processing procedure of a specific experiment.

Below we shortly examine sensitivity of the retrieved profiles, $c_{k}(h)$, to the input data selection for the case of combined lidar/radiometer sounding of the atmospheric aerosol during the last period of Eyjafjallajökull volcano ash transport to the European area in Lille, France, on the 19 May 2010. Air mass back trajectories (Fig. 9) forecasted the possibility of appearance of volcanic ash in the layer between 1300 and $2500 \mathrm{~m}$. The structure of the retrieved profiles, $c_{k}(h)$, shown in Fig. 10a agrees well with the forecast. Deviations (by "deviations" hereinafter we mean "standard deviation") $\delta\left(c_{k}\left(h_{i}\right)\right)$ associated to the profiles $c_{k}(h)$ have been calculated by an "error modelling" procedure similar to the one described in Sect. 6.1.

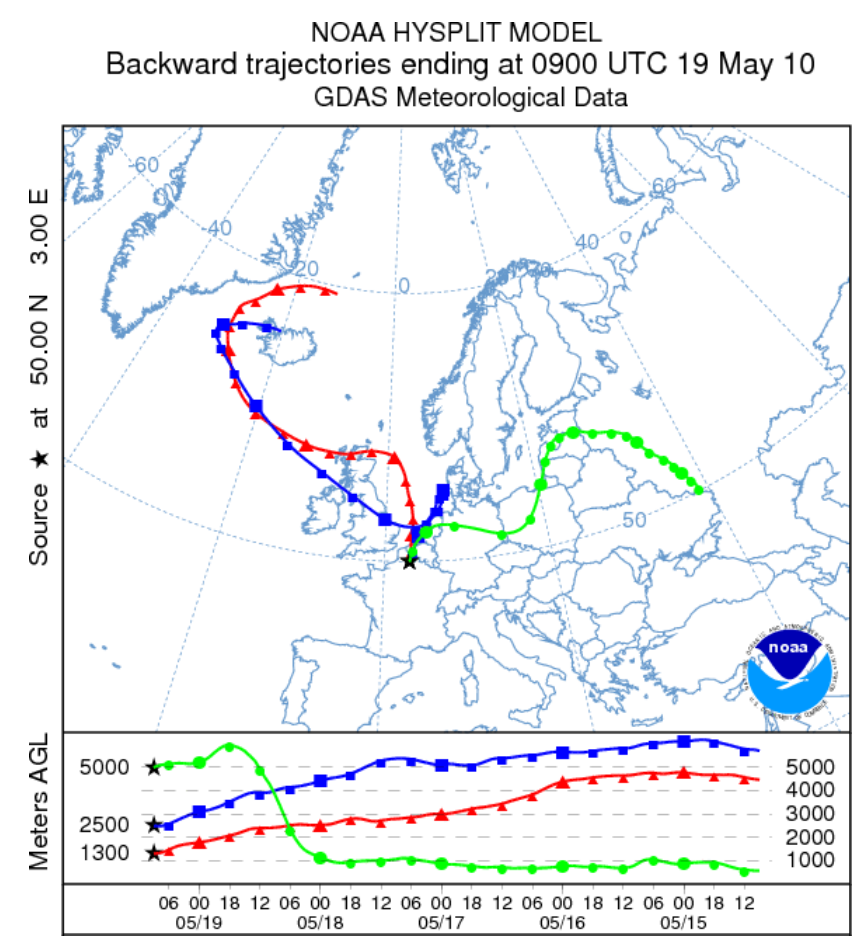

Figure 9. Air-mass back trajectories for Lille at 08:00 UTC, 19 May 2010, (NOAA HYSPLIT model).
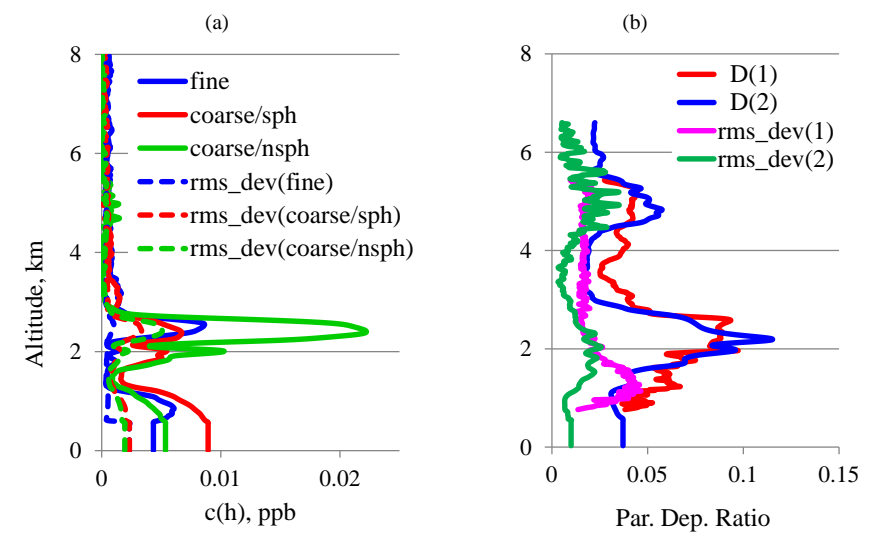

Figure 10. (a), PVC profiles, $c_{k}(h)$, of the fine, course-spherical (coarse/sph) and coarse-nonspherical (coarse/nsph) aerosol modes, and their rms-deviations (rms_dev(fine), rms_dev(coarse/sph), and rms_dev(coarse/nsph)); (b), particle depolarization ratio, D(1) and (2), and their rms-deviations, rms_dev(1) and rms_dev(2). Profiles were retrieved from the data measured in Lille, 19 May 2010, 09:17-09:58 UTC. Profiles D(1) and rms_dev(1) are the results of the direct calculation of depolarization ratio and their rmsdeviations from lidar measurements, as well as D(2) and rms_ev(2) were calculated from retrieved aerosol mode concentrations, $c_{k}(h)$.

A mixture of spherical and non-spherical particles constitutes the aerosol layer at the height of about $2000 \mathrm{~m}$. The profile of particle depolarization ratio at $532 \mathrm{~nm}$ and its deviation have been calculated from the retrieved aerosol mode 


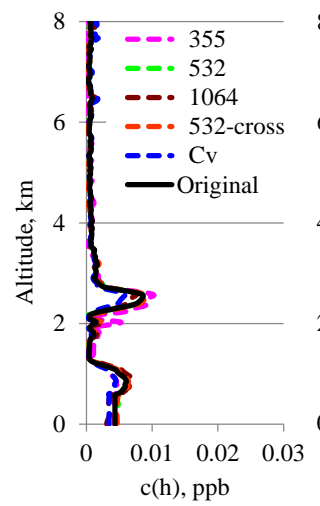

(b)

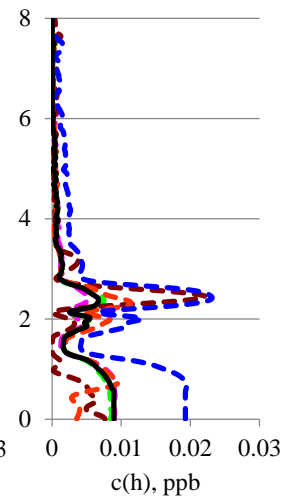

(c)

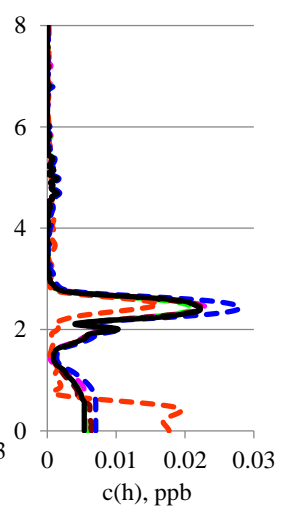

Figure 11. Variation of aerosol concentration profiles, $c_{k}(h)$, for fine (a), coarse spherical (b) and coarse non-spherical (c) aerosol modes in response to elimination of different parts of input information. Tag "Original" denotes complete set of input data; tag "355" (or 532, 1064, 532-cross) denotes that lidar signal at $355 \mathrm{~nm}$ (or 532,

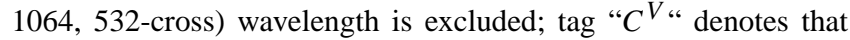
columnar volume concentrations of aerosol modes are excluded. Lille, 08:00 UTC, 19 May 2010.

concentrations, $c_{k}(h)$. The profiles are shown in Fig. 10b, curves D(2) and rms_dev(2). The results of the direct calculation of depolarization ratio and their deviations from lidar measurements are presented by curves $\mathrm{D}(1)$ and rms_dev(1). It should be noted that the lidar measurements included additional calibration measurement that was not used by the retrieval procedure. Profiles $\mathrm{D}(1)$ and $\mathrm{D}(2)$ show rather close agreement in magnitude and vertical structure that could confirm the efficiency of the aerosol modelling used in this study.

The curves in Fig. 11 show the deviations in the retrieved concentration profiles, $c_{k}(h)$, after elimination one of the lidar signals or columnar volume concentrations of aerosol modes, $\boldsymbol{C}^{V}$, from the input data set. As can be seen from Fig. 11, the concentration profile of the fine-particle mode undergoes minor changes upon elimination of a single lidar signal or the elimination of columnar volume concentrations. This could imply that our experiment initially included redundant input information, with respect to the fine-mode concentration. On the other hand, concentrations of coarse modes are sensitive to input information. Thus, lidar data at $1064 \mathrm{~nm}$ wavelength plays a crucial role in the retrieval of the coarse spherical mode. In the same manner, lidar depolarization measurement is the key factor in the retrieval of the coarse spheroid particle mode. Evaluations of columnar volume concentrations from radiometer measurement are necessary for all cases.

Figure 12a shows concentration profiles, $c_{k}(h)$, which were retrieved for two- and three-mode aerosol models and characterized the aerosol layer in the same LRS experiment. The fine-mode concentration profiles for two aerosol models are practically coincident. Profiles $c_{k}(h)$ of coarse modes
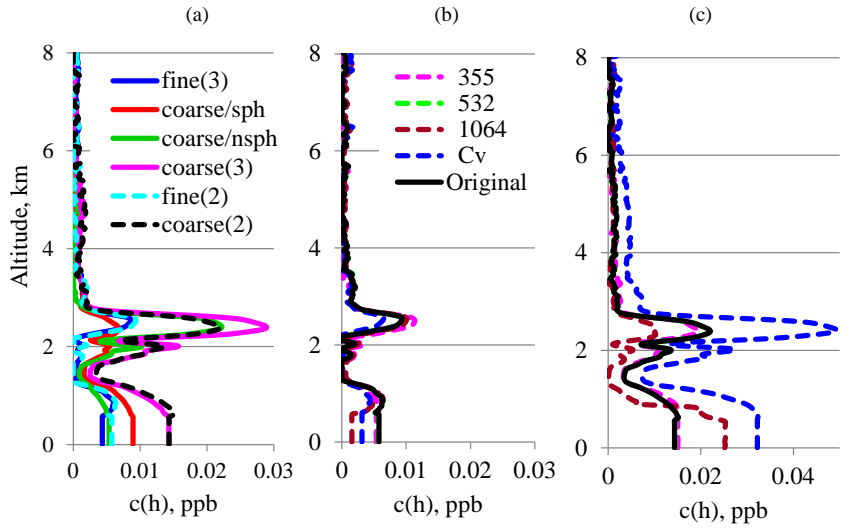

Figure 12. Comparison of PVC profiles, $c_{k}(h)$, for the two- and three-mode aerosol models (a), and variations of concentration profiles, $c_{k}(h)$, for fine (b) and coarse (c) aerosol modes of the twomode aerosol model in response to elimination of different parts of input information. In Fig. 12a tags "fine(2)" and "coarse(2)" denote fine and coarse modes of two-mode aerosol model. Tags "fine(2)", "coarse/sph", "coarse/nsph" and "coarse(3)" denote fine, coarse spherical, course non-spherical and total course mode of three-mode aerosol model, correspondingly. In Fig. 12b and c tag "Original" means complete set of input data; tag " 355 " (or 532, 1064) denotes that the lidar signal at $355 \mathrm{~nm}$ (or 532, 1064) wavelength is excluded; tag " $C$ " "denotes that columnar volume concentrations of aerosol modes are excluded. Lille, 08:00 UTC, 19 May 2010.

for two-mode aerosol model, coarse (2), and the sum of two coarse components for three-mode aerosol model, coarse (3), are similar in shape but quantitatively are a bit different. The column concentrations of the course (2) and (3) modes are equal.

The curves in Figs. 12b and $\mathrm{c}$ show the deviations of the concentration profiles, $c_{k}(h)$, for the two-mode aerosol model after reduction of the input data set. Deviations of $c_{k}(h)$ profiles are rather similar to those for the three-mode aerosol model in Fig. 11. Deviations of fine-mode concentration profile are small, even if any single sub-set of input data is eliminated. Coarse-mode concentration profiles preserve original forms when one of the lidar signals at the 355 or $532 \mathrm{~nm}$ wavelength is excluded from the processing procedure.

Generally, for measurement conditions that characterize the experiment under discussion, two-wavelength lidar sounding (at 355 and 1064 or at 532 and $1064 \mathrm{~nm}$ ) combined with radiometer measurement provides retrieving concentration profiles of fine and coarse aerosol modes for two-mode aerosol model.

\section{Discussion and conclusions}

The active process of dissemination of the LIRIC in EARLINET started in 2012. Nowadays, 11 EARLINET teams participate in implementation of LRS technique (see Fig. 13). 


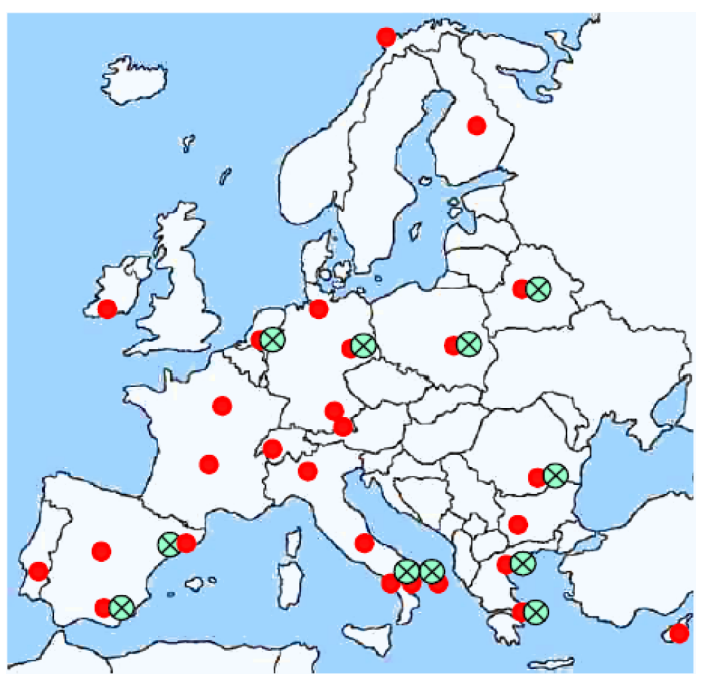

Figure 13. Map of the EARLINET stations (red dots). Green dots indicate the stations where LIRIC program package has been implemented.

New scientific teams beyond EARLINET join the LIRIC user group. The detailed description of LIRIC algorithm and software in this paper should contribute to the effective implementation of the LRS technique by advanced users.

Retrieval of the aerosol parameters from the LRS measurements is an "ill-posed" inverse problem, and its solution should be tested on stability to the measurement errors and variations of the regularization parameters, which are set by the module "Inversion setting and errors moduling" of the software package (Fig. 2). Results of the EARLI09 intercomparison experiment presented in Sect. 6.1 demonstrate rather small scatter in $c_{k}(h)$ profiles that were retrieved from the data of different lidar systems with significantly corrupted input lidar signals and big uncertainties of the aerosol lidar ratio. This scatter is characterized by standard deviations of 5$20 \%$ of the maximum aerosol layer concentration. Increase in $c_{k}(h)$ deviation in the bottom layer results from uncertainties of the overlap function of the lidar systems.

The uncertainties in the retrieved aerosol parameters for different aerosol types, aerosol loads, overlap characteristics of the lidar systems and regularization parameters that are defined by the LIRIC operator were evaluated by GranadosMuñoz et al. (2014). The analysis covered combined lidar and radiometer measurements that were carried out during dust, smoke, and anthropogenic pollution events. This analysis mostly supports our conclusions on the stability of LIRIC solutions that retrieve basic aerosol features even under significant measurement errors. In particular, variations of the regularization parameters within one order interval from the original set lead to minor deviations of the retrieved $c_{k}(h)$ profiles. Usually, it is unnecessary to change recommended utility regularization parameters while homogeneous input data sets are processed. The requirements for pre-processing lidar signals along with the set of recommended regularization parameters are provided in the LIRIC user guide. However, the utility parameters for error modelling menu should be defined by the LIRIC user with regard to the specific lidar system.

The requirement of having possibly minimal "full overlap" height of lidar sensing is an important technical problem for LRS measurements, because the near-surface aerosol layer contributes strongly to the radiometric data. In the absence of lidar data, the surface aerosol layer is assumed to be homogeneous in the LIRIC aerosol modelling. Obviously, aerosol parameters can vary within the near-surface layer resulting in significant uncertainties in the LIRIC product, especially when the lidar "dead zone" becomes comparable to the boundary-layer thickness. The effective solution of this problem is the set-up of a double lidar receiving block with special near-range channels for the detection of near-ground aerosol.

The analysis of the aerosol parameters that are retrieved from the incomplete sets of lidar data in Sect. 6.2 supports the possibility to use LIRIC for processing data of two-wavelength lidar systems. Aerosol sounding by twowavelength lidars, usually at 532 and $1064 \mathrm{~nm}$ wavelengths, is a widespread practice in atmospheric investigations. Simulation results in Sect. 6.2 show the possibility to retrieve $c_{k}(h)$ for two-mode aerosol model. The uncertainties of such evaluated $c_{k}(h)$ are expected to surpass ones of threewavelength lidar sounding.

LIRIC implementation for the special lidar data set (532cross, 532-parallel and $1064 \mathrm{~nm}$ ) for retrieving parameters of the three-mode aerosol model is of interest for the satellite lidar CALIOP that provides similar lidar data (Winker et al, 2006).

Since the beginning of LIRIC dissemination in EARLINET community, experimental works on the validation of the LIRIC product for different aerosol types have being carried out. Comparisons of aerosol backscatter coefficients and depolarization ratios directly derived from lidar data against similar characteristics calculated from the aerosol optical and microphysical parameters retrieved by LIRIC (e.g. Tsekeri et al., 2012, 2013; Wagner et al., 2013; Kokkalis et al., 2013; Granados-Muñoz et al., 2014) as well as LIRIC against modelled or airborne in situ measured profiles of aerosol mode concentrations (e.g. Kokkalis et al., 2012, 2013; Nemuc et al., 2013) have shown reasonable agreement.

The LIRIC concentration profiles of aerosol fractions during dust and volcano ash events have been compared with those for spherical and non-spherical particles derived from polarization measurements using the POLIPHON technique (e.g. Wagner et al., 2013; Nemuc et al., 2013, Papayannis et al., 2014). In spite of the noticeable difference between the aerosol models and independent processing algorithms, the retrieved aerosol concentration profiles have proved to be similar. This is quite natural because both approaches use the 
depolarization of backscatter signal to distinguish between spherical and non-spherical particles.

The number of aerosol studies using LIRIC algorithm increases. They focus on the investigation of the dynamics of aerosol microstructure during transport of air masses polluted by dust (e.g. Chaikovsky et al., 2010b; Tsekeri et al., 2013; Binietoglou et al., 2015; Granados-Muñoz et al., 2015a), fire smoke (e.g. Chaikovsky et al., 2010b; GranadosMuñoz et al., 2015b), volcano ash (Kokkalis et al., 2013) and anthropogenic pollution (Granados-Muñoz et al., 2014). LIRIC has become a tool for validation of the modelling of aerosol transport in atmosphere (Binietoglou et al., 2015; Granados-Muñoz et al., 2015b). EARLINET teams form the data-base of the results of combined lidar and radiometer sounding.

The list of lidar teams that take advantage of LIRIC is still expanding. The LIRIC software package is open and distributed both within the EARLINET community and beyond it. The EARLINET teams provide continuous improvement of the software and cooperate on the implementation of the LRS measurements at new sites. 


\section{Appendix A: General equation for received lidar signal}

Using general formula for received lidar signal instead of Eqs. (4), (6), and (8) allows us to derive compact and explicit expression for the covariance matrices, $\boldsymbol{\Omega}_{L}$, and regularizing term, $\breve{\Psi}_{L}\left(\boldsymbol{L}^{*}, \boldsymbol{c}\right)$ (Sect. 4).

We will use the utility function

$\delta_{p_{j}, u}^{j}=\left\{\begin{array}{c}1 \ldots i f \ldots p_{j}=u \\ 0 \ldots f \ldots p_{j} \neq u\end{array}\right.$,

along with the following definitions of combinations of aerosol and molecular optical parameters in Eqs. (4)-(9):

$$
\begin{aligned}
& \beta_{a}^{\mathrm{ef}}\left(\lambda_{j}, p_{j}, h\right)=\left(\beta_{a, p_{j}}\left(\lambda_{j}, h\right)\right. \\
&\left.+\delta_{p_{j}, 2}^{j} \mu \beta_{a, 3}\left(\lambda_{j}, h\right)\right) \\
&=\left(\sum_{k} c_{k}(h) b_{k, p_{j}}\left(\lambda_{j}\right)\right. \\
&\left.+\delta_{p_{j}, 2}^{j} \mu \sum_{k} c_{k}(h) b_{k, p_{j}}\left(\lambda_{j}\right)\right) \\
& \beta_{r}^{\mathrm{ef}}\left(\lambda_{j}, p_{j}, h\right)=\left(\delta_{p_{j}, 2}^{j}\left(p_{j}\right)\left(\frac{\mu-1}{\chi+1}\right)\right. \\
&\left.+\frac{1}{1+\delta_{p_{j}, 3}^{j}}\right) \beta_{r}\left(\lambda_{j}, h\right) \\
& \beta^{\mathrm{ef}}\left(\lambda_{j}, p_{j}, h\right)= \beta_{a}^{\mathrm{ef}}\left(\lambda_{j}, p_{j}, h\right) \\
&+\beta_{r}^{\mathrm{ef}}\left(\lambda_{j}, p_{j}, h\right) \\
& \tau_{a}\left(\lambda_{j}, h, h_{\mathrm{ref}}\right)= \int_{h}^{\mathrm{ef}}\left(\lambda_{j}, p_{j}, h\right)= \\
& h_{\mathrm{ref}}^{\mathrm{ef}}\left(\lambda_{j}, p_{j}, h\right)+\beta_{r}^{\mathrm{ef}}\left(\lambda_{j}, p_{j}, h\right) \\
& \beta_{r}^{\mathrm{ef}}\left(\lambda_{j}, p_{j}, h\right)
\end{aligned}
$$

This permits Eqs. (4), (5) and (8) to be written in general form:

$L_{j}\left(p_{j}, \lambda_{j}, h\right)=\frac{\beta^{\mathrm{ef}}\left(\lambda_{j}, p_{j}, h\right) \exp \left(2 \tau_{a}\left(\lambda_{j}, h, h_{\mathrm{ref}}\right)\right)}{\beta_{r}^{\mathrm{ef}}\left(\lambda_{j}, p_{j}, h_{\mathrm{ref}}\right) \hat{R}_{j}^{\mathrm{ef}}\left(\lambda_{j}, p_{j}, h_{\mathrm{ref}}\right)}$.
Therefore, the related to the lidar objective function, $\breve{\Psi}_{L}\left(\boldsymbol{L}^{*}, \boldsymbol{c}\right),($ Eq. 25$)$, is given by the equation:

$$
\begin{aligned}
& \breve{\Psi}_{L}\left(\boldsymbol{L}^{*}, \boldsymbol{c}\right)=\sum_{j} \sum_{i} \frac{\Delta h_{i}}{\breve{\Omega}_{L_{j}}(i, i)} \\
& \left(\begin{array}{c}
L_{j, i}^{*}-\frac{\left(\sum_{k} c_{k}\left(h_{i}\right) b_{k, p_{j}}\left(\lambda_{j}\right)+\delta_{p, 2}^{j} \mu \sum_{k} c_{k}\left(h_{i}\right) b_{k, p_{j}}\left(\lambda_{j}\right)\right)}{\beta_{r}^{\mathrm{ef}}\left(\lambda_{j}, p_{j}, h_{\mathrm{ref}}\right) \hat{R}_{j}^{\mathrm{ef}}\left(\lambda_{j}, p_{j}, h_{\mathrm{ref}}\right)} \\
\times \exp \left(2 \sum_{k} \sum_{i} c_{k}\left(h_{i}\right) a_{k}\left(\lambda_{j}\right) \Delta h_{i}\right)
\end{array}\right)
\end{aligned}
$$

$i \in 1, \ldots I$.

Equation (26), $\breve{\Psi}_{V}\left(\hat{\boldsymbol{C}}^{* V}, \boldsymbol{c}\right)$, which brings radiometer data into the processing procedure can be expressed as follows:

$$
\begin{aligned}
\breve{\Psi}_{V}\left(\hat{\boldsymbol{C}}^{* V}, \boldsymbol{c}\right)= & \sum_{k} \frac{1}{\breve{\Omega}_{V}(k, k)} \\
& \left(\hat{\boldsymbol{C}}^{* V}-\sum_{i} c_{k}\left(h_{i}\right)\left|\Delta h_{i}\right|\right)^{2} .
\end{aligned}
$$

Calculation of the "smoothness" part of the objective function is described in details in Dubovik, 2004; and Dubovik et al., 2011 .

\section{Appendix B: Evaluation of covariance matrix $\Omega_{L}$}

The covariance matrixes, $\boldsymbol{\Omega}_{L}, \boldsymbol{\Omega}_{V}$, and $\boldsymbol{\Omega}_{2}$, defined in Sect. 4 characterize uncertainties of the complex input vector, $\left(\boldsymbol{L}^{*}, \hat{\boldsymbol{C}}^{* V}, \hat{\mathbf{0}}\right)$, where $\hat{\mathbf{0}}$ is "zero" vector that is defined to formalize a priori smoothness restrictions on concentration profiles (e.g. Dubovik, 2004). These matrices determine the "weights" of different parts of input information through the minimization procedure of the objective function (Eq. 22).

In our case the measure of the smoothness for concentration profiles, $c_{k}\left(h_{i}\right)$, should be chosen as a priori evaluated parameters. Aerosol columnar volume concentrations, $\hat{\boldsymbol{C}}^{* V}$, and variances, $\Omega_{V}(k, k)$, are the parts of input radiometer data. Thus, only evaluation of covariance matrix, $\boldsymbol{\Omega}_{L}$, is to be done.

The assumption of independent normal distribution for variations of "lidar" vector, $\boldsymbol{L}^{*}$, at different heights implies the diagonal covariance matrix. The non-zero diagonal elements, $\Omega_{L_{j}}\left(h_{i}, h_{i}\right)$, of the covariance matrix are the variances of differences between the components, $L_{j, i}^{*}$, of the lidar vector and the appropriate modelled function, $L_{j}\left(c_{k}, p_{j}, \lambda_{j}, h_{i}\right)$, in Eq. (A7). 
Given Eqs. (2), (3) and (A1)-(A-8), the elements of vector, $\Delta_{L_{j}}$, are defined by the following:

$$
\begin{aligned}
\Delta_{L_{j}}\left(h_{i}\right)= & L_{j, i}^{*}-L_{j}\left(p_{j}, \lambda_{j}, h_{i}\right) \\
= & \frac{S^{*}\left(\lambda_{j}, h_{i}\right)}{\hat{S}^{*}\left(\lambda_{j}, h_{\mathrm{ref}}\right)} \exp \left(-2 \tau_{r}\left(\lambda_{j}, h_{i}, h_{\mathrm{ref}}\right)\right) \\
& -\frac{\beta^{\mathrm{ef}}\left(\lambda_{j}, p_{j}, h_{i}\right) \exp \left(2 \tau_{a}\left(\lambda_{j}, h_{i}, h_{\mathrm{ref}}\right)\right)}{\beta_{r}^{\mathrm{ef}}\left(\lambda_{j}, p_{j}, h_{\mathrm{ref}}\right) \hat{R}_{j}^{\mathrm{ef}}\left(\lambda_{j}, p_{j}, h_{\mathrm{ref}}\right)} .
\end{aligned}
$$

Using the finite differences technique (e.g. Russell et al., 1979) one can expand $\Delta_{L_{j}}\left(h_{i}\right)$ in Taylor series, and then neglect all the terms of the second or higher order. As a result, variation $\delta\left(\Delta_{L_{j}}\left(h_{i}\right)\right)$ can be expressed as a function of variations related with the input parameters, $\delta\left(S^{*}\left(\lambda_{j}, h_{i}\right)\right)$, $\delta\left(\beta^{\text {ef }}\left(\lambda_{j}, p_{j}, h_{i}\right)\right), \delta\left(\tau_{a}\left(\lambda_{j}, h_{i}, h_{\mathrm{ref}}\right)\right.$, and $\delta\left(\tau_{r}\left(\lambda_{j}, h_{i}, h_{\mathrm{ref}}\right)\right)$ :

$$
\begin{aligned}
\delta\left(\Delta_{L_{j}}\left(h_{i}\right)\right)= & -2 L_{j, i}^{*} \delta\left(\tau_{r}\left(\lambda_{j}, h_{i}, h_{\mathrm{ref}}\right)\right) \\
& +L_{j, i}^{*} \frac{\delta\left(S^{*}\left(\lambda_{j}, h_{i}\right)\right)}{S^{*}\left(\lambda_{j}, h_{i}\right)} \\
& +\frac{\beta^{\mathrm{ef}}\left(\lambda_{j}, p_{j}, h_{i}\right) \exp \left(2 \tau_{a}\left(\lambda_{j}, h_{i}, h_{\mathrm{ref}}\right)\right)}{\beta_{r}^{\mathrm{ef}}\left(\lambda_{j}, p_{j}, h_{\mathrm{ref}}\right) \hat{R}_{j}^{\mathrm{ef}}\left(\lambda_{j}, p_{j}, h_{\mathrm{ref}}\right)} \\
& \frac{\delta\left(\beta^{\mathrm{ef}}\left(\lambda_{j}, p_{j}, h_{i}\right)\right)}{\beta^{\mathrm{ef}}\left(\lambda_{j}, p_{j}, h_{i}\right)} \\
& -2 \frac{\beta^{\mathrm{ef}}\left(\lambda_{j}, p_{j}, h_{i}\right) \exp \left(2 \tau_{a}\left(\lambda_{j}, h_{i}, h_{\mathrm{ref}}\right)\right)}{\beta_{r}^{\mathrm{ef}}\left(\lambda_{j}, p_{j}, h_{\mathrm{ref}}\right) \hat{R}_{j}^{\mathrm{ef}}\left(\lambda_{j}, p_{j}, h_{\mathrm{ref}}\right)} \\
& \delta\left(\tau_{a}\left(\lambda_{j}, h_{i}, h_{\mathrm{ref}}\right)\right. \\
& \approx L_{j, i}^{*}\left(\frac{\delta\left(S^{* j}\left(h_{i}\right)\right)}{S^{* j}\left(h_{i}\right)}-\frac{\delta\left(\beta^{\mathrm{ef}}\left(\lambda_{j}, p_{j}, h_{i}\right)\right)}{\beta^{\mathrm{ef}}\left(\lambda_{j}, p_{j}, h_{i}\right)}\right. \\
& -2 \delta\left(\tau_{r}\left(\lambda_{j}, h_{i}, h_{\mathrm{ref}}\right)\right) \\
& \left.-2 \delta\left(\tau_{a}\left(\lambda_{j}, h_{i}, h_{\mathrm{ref}}\right)\right)\right) .
\end{aligned}
$$

Under the assumption of independent variations of different parameters, the variance $\Omega_{L}\left(h_{i}, h_{n}\right)$ is expressed as follows

$$
\begin{aligned}
\Omega_{L}\left(h_{i}, h_{i}\right)= & \left\langle\delta\left(\Delta_{L_{j}}\left(h_{i}\right)\right) \delta\left(\Delta_{L_{j}}\left(h_{i}\right)\right)\right\rangle \\
= & L_{j, n}^{* 2}\left(\frac{\delta^{2}\left(P_{j, i}^{*}\right)}{\left(P_{j, i}^{*}\right)^{2}}+\frac{\delta^{2}\left(\beta^{\mathrm{ef}}\left(\lambda_{j}, p_{j}, h_{i}\right)\right)}{\left(\beta^{\mathrm{ef}}\left(\lambda_{j}, p_{j}, h_{i}\right)\right)^{2}}\right. \\
& +4 \delta^{2}\left(\tau_{r}\left(\lambda_{j}, h_{i}, h_{\mathrm{ref}}\right)\right) \\
& \left.+4 \delta^{2}\left(\tau_{a}\left(\lambda_{j}, h_{i}, h_{\mathrm{ref}}\right)\right)\right),
\end{aligned}
$$

where $\langle\ldots\rangle$ denotes ensemble averaging over measurement realizations, and $P_{j, i}^{*}=P_{j}^{*}\left(h_{i}\right)$.

The terms in the large round parentheses in Eq. (B3) determine contributions of measurement errors and uncertainties of a priori defined optical characteristics. We aim at approximate estimation of $\Omega_{L_{j}}\left(h_{i}, h_{i}\right)$ at the preprocessing stage without involving of retrieved parameters. This feedbackfree approach greatly simplifies the structure of the inversion algorithm.

\section{Uncertainties of the optical parameters}

The term $\delta^{2}\left(\beta^{\text {ef }}\right) /\left(\beta^{\text {ef }}\right)^{2}$ in Eq. (B3) is the relative variance of the total backscatter coefficient. It can be transformed into the sum of relative variances of aerosol and molecular backscatter coefficients:

$$
\begin{aligned}
\frac{\delta^{2}\left(\beta^{\mathrm{ef}}\left(\lambda_{j}, p_{j}, h_{i}\right)\right)}{\left(\beta^{\mathrm{ef}}\left(\lambda_{j}, p_{j}, h_{i}\right)\right)^{2}}= & \frac{\delta^{2}\left(\beta_{r}^{\mathrm{ef}}\left(\lambda_{j}, p_{j}, h_{i}\right)\right)}{\left(\beta_{r}^{\mathrm{ef}}\left(\lambda_{j}, p_{j}, h_{i}\right)\right)^{2}} \\
& \frac{1}{\left(\hat{R}_{j}^{\mathrm{ef}}\left(\lambda_{j}, p_{j}, h_{i}\right)\right)^{2}} \\
& +\frac{\delta^{2}\left(\beta_{a}^{\mathrm{ef}}\left(\lambda_{j}, p_{j}, h_{i}\right)\right)}{\left(\beta_{a}^{\mathrm{ef}}\left(\lambda_{j}, p_{j}, h_{i}\right)\right)^{2}} \\
& \frac{\left(\hat{R}_{j}^{\mathrm{ef}}\left(\lambda_{j}, p_{j}, h_{i}\right)-1\right)^{2}}{\left(\hat{R}_{j}^{\mathrm{ef}}\left(\lambda_{j}, p_{j}, h_{i}\right)\right)^{2}} .
\end{aligned}
$$

The International Standard Atmosphere ISO 2533 and seasonal latitudinal changed model CIRA (Committee on Space Research (COSPAR), 2006; Fleming et al., 1988), as well as measurements by radiosondes are applied in LIRIC for the calculation of molecular optical parameters. The relative variance of calculated molecular backscatter coefficient

$\alpha_{1}^{2}=\frac{\delta^{2}\left(\beta_{r}^{\mathrm{ef}}\left(\lambda_{j}, p_{j}, h_{i}\right)\right)}{\left(\beta_{r}^{\mathrm{ef}}\left(\lambda_{j}, p_{j}, h_{i}\right)\right)^{2}}$

is assumed to be a constant and its value can be reduced to $\alpha_{1}=0.01$ (e.g. Russell et al., 1979) if data of coordinated radiosonde measurements are available.

The aerosol backscatter coefficients, $\beta_{a}^{\text {ef }}\left(\lambda_{j}, p_{j}, h_{i}\right)$, are estimated by using Eqs. (10)-(17). Uncertainties of $\beta_{a}^{\text {ef }}\left(\lambda_{j}, p_{j}, h_{i}\right)$ basically follow from estimation errors of the coefficient $b\left(v, j, p_{j}\right)$ in Eqs. (15)-(17) that can be written by the equation:

$b\left(j, p_{j}, k\right)=\frac{1}{\vartheta_{k, p}^{j}} \frac{E_{k}^{*}\left(\lambda_{j}\right)}{\hat{C}_{k}^{V}}$,

where

$\frac{1}{\vartheta_{k, p}^{j}}=\frac{1}{4 \pi} \varpi_{k}\left(\lambda_{j}\right) A_{k, p}^{j}$,

$A_{k, p}^{j}=\left\{\begin{array}{ccc}P_{1,1}^{v}\left(\lambda_{j}, \gamma=180^{\circ}\right) & \text { if } & p_{j}=1 \\ \frac{P_{1,1}^{k}\left(\lambda_{j}, \gamma=180^{\circ}\right)-P_{2,2}^{k}\left(\lambda_{j}, \gamma=180^{\circ}\right)}{2} & p_{j}=2 . \\ \frac{P_{1,1}^{k}\left(\lambda_{j}, \gamma=180^{\circ}\right)+P_{2,2}^{k}\left(\lambda_{j}, \gamma=180^{\circ}\right)}{2} & p_{j}=3\end{array}\right.$ 
Parameter $\vartheta_{k, p}^{j}=\sigma_{a}^{k}\left(\lambda_{j}, h_{i}\right) / \beta_{a}^{\mathrm{ef}, \mathrm{k}}\left(\lambda_{j}, h_{i}\right)$ in Eq. (B8) is the extinction-to-backscatter ratio or "lidar ratio" of the $k$ aerosol mode.

Parameters $\vartheta_{k, p}^{j}$ are retrieved from the data of radiometric direct sun and almucantar measurements that are usually performed with the maximum scattering angle less than $150^{\circ}$. The range of the scattering angles decreases as the sun zenith angle decreases. Retrieval of optical parameters in the backscatter direction, in a certain sense, is an extrapolation procedure out of the measured range with possible increasing of estimation uncertainties. One assumes that the errors of the estimation of $\vartheta_{k, p}^{j}$ are the main reason of the incorrect calculation of backscatter coefficients $\beta_{a}^{\mathrm{ef}}\left(\lambda_{j}, p_{j}, h_{i}\right)$ and introduces parameter $\alpha_{2}$ for characterization of the standard deviation of coefficients $1 / \vartheta_{k, p}^{j}$ in LRS measurements.

Thus, Eq. (B4) is transformed to

$$
\begin{aligned}
\frac{\delta^{2}\left(\beta^{\mathrm{ef}}\left(\lambda_{j}, p_{j}, h_{i}\right)\right)}{\left(\beta^{\mathrm{ef}}\left(\lambda_{j}, p_{j}, h_{i}\right)\right)^{2}}= & \frac{\alpha_{1}^{2}}{\left(R_{j}^{\mathrm{ef}}\left(\lambda_{j}, p_{j}, h_{i}\right)\right)^{2}} \\
& +\alpha_{2}^{2} \frac{\left(R_{j}^{\mathrm{ef}}\left(\lambda_{j}, p_{j}, h_{i}\right)-1\right)^{2}}{\left(R_{j}^{\mathrm{ef}}\left(\lambda_{j}, p_{j}, h_{i}\right)\right)^{2}} .
\end{aligned}
$$

The backscatter ratio $R_{j}^{\mathrm{ef}}\left(\lambda_{j}, p_{j}, h_{i}\right)$ in Eq. (B9) under assumption $\mu=0$ is approximately calculated at the preprocessing stage using the Klett algorithm (Klett, 1981).

Basically, the variance of aerosol optical thickness, $\delta^{2}\left(\tau_{a}\left(\lambda_{j}, h_{i}, h_{\text {ref }}\right)\right)$, arises from altitude variations of aerosol modes that are not assumed by the aerosol model. Relative error of $\tau_{a}\left(\lambda_{j}, h_{i}, h_{\text {ref }}\right)$ is zero at the reference point and is equal to $\alpha_{3}^{2}$ at the start point $h_{1}$, where $\alpha_{3}$ is close to the error of AOT calculation from radiometer measurements. Thus, the following approximation is used in the LIRIC algorithm:

$\delta^{2}\left(\tau_{a}\left(\lambda_{j}, h_{i}, h_{\text {ref }}\right)\right)=\alpha_{3}^{2} \tau_{a}^{2}\left(\lambda_{j}, h_{i}, h_{\text {ref }}\right)$.

Term $\delta^{2}\left(\tau_{r}\left(\lambda_{j}, h_{i}, h_{\text {ref }}\right)\right)$ in Eq. (B3) denotes the variance of molecular optical thickness of the atmospheric layer $\left(h_{n}, h_{\text {ref }}\right)$. Only long-scale or systematic deviations of molecular density contribute to the variance $\delta^{2}\left(\tau_{r}\left(\lambda_{j}, h_{i}, h_{N}\right)\right)$. Similar to Eq. (B10),

$\delta^{2}\left(\tau_{r}\left(\lambda_{j}, h_{i}, h_{\mathrm{ref}}\right)\right)=\alpha_{4}^{2} \tau_{r}^{2}\left(\lambda_{j}, h_{i}, h_{\mathrm{ref}}\right)$.

\section{Measurement errors}

Optical signals, detected by the lidar data acquisition system consists of backscatter $P_{j, i}^{*}$ and background $B_{j}^{*}$ components. A suitable algorithm for estimating the measurement errors is described by Slesar et al. (2013, 2015). Regardless of the type of the photo-receiving sensor, three factors determine the measurement errors:

- non-linearity of the recording channel, which consist of nonlinearity of the photodetector and electronic units;
_ "non-synchronous" noise (non-correlated with the sounding pulse);

- "synchronized" noise (correlated with the sounding pulse).

Non-linearity of a receiving channel basically originates from saturation of an output signal at high incident light because of photo-sensor or electronic unit limitations. Likewise, deviations of an amplifier gain cause linear distortions of the detecting signal within the working range of photoreceiving module.

Basic difference between two types of noise is that "nonsynchronous" noise can be reduced by accumulation of input signals or by decreasing frequency bandwidth of the receiving channel, while this method is ineffective for "synchronized" noise. The main type of the "non-synchronous" noise is the Schottky noise. "Synchronous" noise is basically caused by the interference of the electrical impulses from the laser power supply, synchronous with the sounding optical pulse. It is predominantly a low-frequency noise, and acceptable limitation of the frequency band of the photo-receiving channel does not lead to its decline.

We assume that the accumulation of the receiving lidar signal with $A$ sounding pulses and the averaging of the lidar signal over $2 \mathrm{M}+1$ bins are carried out at the measurement and pre-processing stages.

Summing up the contributions of the noise components, one can write the following expression for the variances of the receiving analog and photon-counting signals (Slesar et al., 2013, 2015):

- for the analog channel:

$$
\begin{aligned}
\frac{\delta^{2}\left(P_{j, i}^{*}\right)}{\left(P_{j, i}^{*}\right)^{2}}= & \omega_{j}^{2} \frac{\left(P_{j, n}^{*}+B_{j}^{*}\right)^{2}}{\left(P_{j, n}^{*}\right)^{2}} \\
& +\frac{\left(G_{j}^{*}\right)^{2}+q_{j}^{2}\left(P_{j, n}^{*}+B_{j}^{*}\right)}{A(2 M+1)\left(P_{j, n}^{*}\right)^{2}} \\
& +\frac{\left(U_{j}^{*}\right)^{2}}{\left(P_{j, n}^{*}\right)^{2}},
\end{aligned}
$$

where $\omega$ is the coefficient of nonlinearity, $G_{j}^{*}$ is the amplitude of electrical noise, $q_{j}^{2}$ is the coefficient characterizing the power of the Schottky noise, $U_{j}^{*}$ is the amplitude of "synchronized" noise; 
- for the counting channel:

$$
\begin{aligned}
\frac{\delta^{2}\left(N_{j, i}^{*}\right)}{\left(N_{j, i}^{*}\right)^{2}}= & \omega_{j}^{2} \frac{\left(N_{j, i}^{*}+N_{j, B}\right)^{2}}{\left(N_{j, i}^{*}\right)^{2}} \\
& +\frac{\left(N_{j, G}^{*}\right)^{2}+N_{j, i}^{*}+N_{j, B}}{A(2 M+1)\left(N_{j, i}^{*}\right)^{2}} \\
& +\frac{\left(N_{j, U}^{*}\right)^{2}}{\left(N_{j, i}^{*}\right)^{2}},
\end{aligned}
$$

where $N_{j, i}^{*}$ is the detected lidar signal, $N_{j, B}$ is the background signal, $N_{j, G}$ is the external "non-synchronous" noise, and $N_{j, U}^{*}$ is "synchronized" noise.

Parameters $\omega_{j}, G_{j}^{*}, N_{j, G}^{*}, q_{j}, U_{j}^{*}, N_{j, G}^{*}, N_{j, U}^{*}$ for specific photo-receiving module can be evaluated on a dedicated test bench by means of special calibration procedures (Slesar et al., 2013, 2015).

\section{Appendix C: Details of inversion procedure}

One can understand intuitively that optical parameters of aerosol modes, which constitute the aerosol model (see Sect. 1.1), should be different to allow retrieving aerosol mode concentrations by means of algorithm described in Sect. 4. More correct definition of this is that there should not be a linear relationship between the sets of coefficients $\left\{\mathbf{a}_{k}, \mathbf{b}_{k}\right\}$ which define optical characteristics of $k$ th aerosol mode. This conclusion results from the linear approximation of the Eq. (2). It means that we seek the solution, $c\left(h_{i}\right)$, only from data of multi-wavelength lidar sounding. The linear least squares solution of Eq. (3) can be written as

$\boldsymbol{c}=\left(\mathbf{K}_{L}^{T} \boldsymbol{\Omega}_{L}^{-1} \mathbf{K}_{L}\right)^{-1} \mathbf{K}_{L}^{T} \boldsymbol{\Omega}_{L}^{-1} \mathbf{L}^{*}$,

where $\mathbf{K}_{L}$ is the Jacobi matrix of the first partial derivatives $\left\{\mathbf{K}_{L}\right\}_{x, y}=\delta L_{x} /\left.\delta c_{y}\right|_{\boldsymbol{c}}$. The following definitions are used in Eq. (C1) for measured vector, $\hat{\boldsymbol{L}}^{*}$ and state vector, $\boldsymbol{c}$, with dimensions $J I \times 1$ and $K I \times 1$, correspondingly:

$L_{j, i}^{*}=\left\{\begin{array}{c}L_{1}^{*}\left(h_{1}\right) \\ L_{2}^{*}\left(h_{1}\right) \\ \ldots \\ L_{j}^{*}\left(h_{i}\right) \\ \ldots \\ L_{J}^{*}\left(h_{I}\right)\end{array} \quad, \quad c_{k, i}=\left\{\begin{array}{c}c_{1}\left(h_{1}\right) \\ c_{2}\left(h_{1}\right) \\ \ldots \\ c_{k}\left(h_{i}\right) \\ \ldots \\ c_{K}\left(h_{I}\right)\end{array}\right.\right.$.

The formula (C1) is valid if $\operatorname{det}\left(\mathbf{U}_{L}=\mathbf{K}_{L}^{T} \boldsymbol{\Omega}_{L}^{-1} \mathbf{K}_{L}\right) \neq 0$.

We use additional requirements that optical thickness of the aerosol layer is small, and the variances of the measured errors, $\left(\varepsilon_{L, 1}^{2}, \varepsilon_{L, i}^{2}, \varepsilon_{L, I}^{2}\right)$, do not depend on $h_{i}$. So the matrix

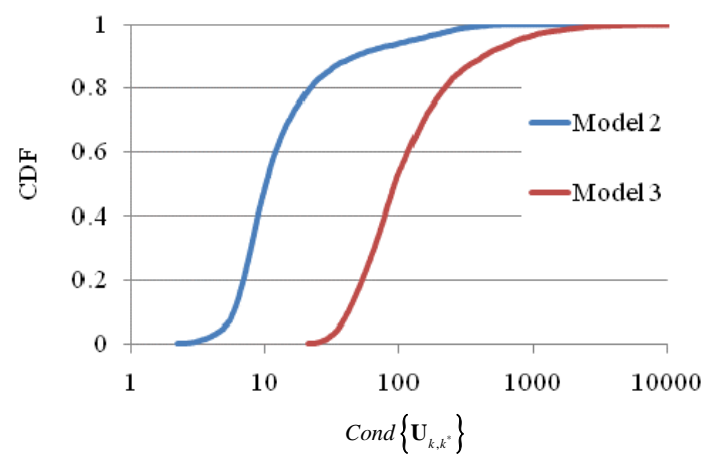

Figure C1. Cumulative distribution functions (CDFs) of parameter Cond $\left\{\mathbf{U}_{k, k^{*}}\right\}$ (condition number) calculated from radiometer data of the AERONET station in Minsk for two- and three-fraction aerosol models, Model 2 and Model 3, respectively.

$\mathbf{U}_{L}=\mathbf{K}_{L}^{T} \boldsymbol{\Omega}_{L}^{-1} \mathbf{K}_{L}$ with dimensions $K I \times K I$ takes the blockdiagonal form

$U_{L}=\left[\begin{array}{ccccc}\frac{1}{\varepsilon_{1}^{2}} \mathbf{U}_{k, k^{*}} & \ldots & & & \\ & & \ldots & & \\ & \cdots & \frac{1}{\varepsilon_{i}^{2}} \mathbf{U}_{k, k^{*}} & \ldots & \\ & & \ldots & & \\ & & & \ldots & \frac{1}{\varepsilon_{I}^{2}} \mathbf{U}_{k, k^{*}}\end{array}\right]$,

where matrix $\mathbf{U}_{k, k^{*}},(k \in 1, \ldots, K)$, does not depend on the superscript $i$. For 3-mode aerosol model $(K=3)$ and 4-channel lidar measurements $(J=4)$ matrix $\mathbf{U}_{k, k^{*}}$ can be written

$\mathbf{U}_{k, k^{*}}=$

$\left[\begin{array}{ccc}\sum_{j} b^{2}\left[j, p_{j}, 1\right] & \sum_{j} b\left[j, p_{j}, 1\right] b\left[j, p_{j}, 2\right] & \sum_{j} b\left[j, p_{j}, 1\right] b\left[j, p_{j}, 3\right] \\ \sum_{j} b\left[j, p_{j}, 1\right] b\left[j, p_{j}, 2\right] & \sum_{j} b^{2}\left[j, p_{j}, 2\right] & \sum_{j} b\left[j, p_{j}, 2\right] b\left[j, p_{j}, 3\right] \\ \sum_{j} b\left[j, p_{j}, 1\right] b\left[j, p_{j}, 3\right] & \sum_{j} b\left[j, p_{j}, 2\right] b\left[j, p_{j}, 3\right] & \sum_{j} b^{2}\left[j, p_{j}, 3\right]\end{array}\right]$

Thus, results of the retrieval depend on the specifics of matrix $\mathbf{U}_{k, k^{*}}$. The well-conditioned matrix $\mathbf{U}_{k, k^{*}}$ provides suitable solution of Eq. (3). On the analogy with Veselovskii et al. (2005), the eigenvalue decomposition technique has been used to evaluate the "condition number" of matrix $\mathbf{U}_{k, k^{*}}$

Cond $\left\{\mathbf{U}_{k, k^{*}}\right\}=\left|\psi_{\max }\right| /\left|\psi_{\min }\right|$,

where $\psi_{\max }$ and $\psi_{\min }$ are the maximum and minimum eigenvalues of matrix, $\mathbf{U}_{k, k^{*}}$ respectively. Parameter $\sqrt{\operatorname{Cond}\left\{\mathbf{U}_{k, k^{*}}\right\}}$ is a coefficient of increasing relative error of $c_{k, i}$ as compared to the relative error of $L_{n, j}^{*}$ estimation (Trefethen and Bau, 1997).

The data of radiometric measurements in Minsk during 2002-2010 were used to calculate the parameters Cond $\left\{\mathbf{U}_{k, k^{*}}\right\}$ for the aerosol models with two and three 
aerosol fractions (three and four measuring channels, correspondingly). The cumulative distribution functions (CDFs) of parameter Cond $\left\{\mathbf{U}_{k, k^{*}}\right\}$ is shown in Fig. (C1).

Matrix $\mathbf{U}_{k, k}$ is sufficiently well conditioned for the twofraction aerosol model, and solution (C1) is applicable for the calculation of aerosol mode concentrations. In the case of the three-fractional aerosol model, parameters Cond $\left\{\mathbf{U}_{k, k^{*}}\right\}$ increase approximately by 10 , and the matrix $\mathbf{U}_{k, k^{*}}$ becomes ill- conditioned. In a case such as this, we have to involve the Eq. (18) in retrieving procedure, i.e. to use information on parameter $\hat{\boldsymbol{C}}^{* V}$ from radiometric measurements. With our definitions, matrix $\mathbf{H}$ in Eq. (18) is written as

$$
\begin{aligned}
& \mathbf{H}_{K \times I K}= \\
& {\left[\begin{array}{cccccccccc}
\Delta h_{1} & \ldots & 0 & \Delta h_{2} & \ldots & 0 & \ldots & \Delta h_{I} & \ldots & 0 \\
0 & \Delta h_{1} & 0 & 0 & \ldots & 0 & \ldots & 0 & \ldots & 0 \\
\ldots & \ldots & \ldots & \ldots & \ldots & \ldots & \ldots & \ldots & \ldots & \ldots \\
0 & \ldots & \Delta h_{1} & 0 & \ldots & \Delta h_{2} & \ldots & 0 & \ldots & \Delta h_{I}
\end{array}\right] .}
\end{aligned}
$$

Finally, a priori smoothness restrictions are used as the additional factor for regularizing the "ill-posed" problem solution. 
Acknowledgements. The financial support by the European Union's Horizon 2020 research and innovation programme (ACTRIS-2, grant agreement no. 654109) is gratefully acknowledged. The background of LIRIC algorithm and software was developed under the ACTRIS Research Infrastructure project, grant agreement no. 262254, within the European Union Seventh Framework Programme, which financial support is gratefully acknowledged.

The authors are very thankful to AERONET community for establishing and maintaining the radiometer network and its information system that provides the excellent tools for aerosol studying and became the base for our work. The authors also thank Tom L. Kucsera (GESTAR/USRA) for back trajectories available at the http://aeronet.gsfc.nasa.gov website.

The authors gratefully acknowledge the Naval Research Laboratory (NRL) for the provision of the NAAPS results and the NOAA Air Resources Laboratory (ARL) for the provision of the HYSPLIT transport and dispersion model used in this publication.

I. Binietoglou received funding from the European Union's Seventh Framework Programme for research, technological development and demonstration under the grant agreement no. 289923 ITARS.

Edited by: N. Sugimoto

\section{References}

Ansmann, A., Baars, H., Tesche, M., Müller, D., Althausen, D., Engelmann, R., Pauliquevis, T., and Artaxo, P.: Dust and smoke transport from Africa to South America: Lidar profiling over Cape Verde and the Amazon rainforest. Geophys. Res. Lett., 36, L11802, doi:10.1029/2009GL037923, 2009.

Ansmann, A., Tesche, M., Groß, S., Freudenthaler, V., Seifert, P., Hiebsch, A., Schmidt, J., Wandinger, U., Mattis, I., Müller, D., and Wiegner, M.: The 16 April 2010 major volcanic ash plume over central Europe: EARLINET lidar and AERONET photometer observations at Leipzig and Munich, Germany, Geophys. Res. Lett., 37, L13810, doi:10.1029/2010GL043809, 2010.

Ansmann, A., Tesche, M., Seifert, P., Groß, S., Freudenthaler, V., Apituley, A., Wilson, K. M., Serikov, I., Linné, H., Heinold, B., Hiebsch, A., Schnell, F., Schmidt, J., Mattis, I., Wandinger, U., and Wiegner, M.: Ash and fine mode particle mass profiles from EARLINET/AERONET observations over central Europe after the eruptions of the Eyjafjallajokull volcano in 2010, J. Geophys. Res., 116, D00U02, doi:10.1029/2010JD015567, 2011.

Ansmann, A., Seifert, P., Tesche, M., and Wandinger, U.: Profiling of fine and coarse particle mass: case studies of Saharan dust and Eyjafjallajökull/Grimsvötn volcanic plumes, Atmos. Chem. Phys., 12, 9399-9415, doi:10.5194/acp-12-9399-2012, 2012.

Antuña, J. C., Landulfo, E., Clemesha, B., Zaratti, F., Quel, E., Bastidas, A., Estevan, R., and Barja, B.: Lidar community in Latin America: a decade of challenges and successes: in Reviewed and Revised Papers Presented at the 26th International Laser Radar Conference (ILRC 2012), 25-29 June 2012, Porto Heli, Greece, 323-326, 2012.

Biele, J., Beyerle, G. and Baumgarten G.: Polarization lidar: corrections of instrumental effects, Opt. Express 7, 427-435, 2000.

Binietoglou, I., Basart, S., Alados-Arboledas, L., Amiridis, V., Argyrouli, A., Baars, H., Baldasano, J. M., Balis, D., Belegante,
L., Bravo-Aranda, J. A., Burlizzi, P., Carrasco, V., Chaikovsky, A., Comerón, A., D’Amico, G., Filioglou, M., Granados-Muñoz, M. J., Guerrero-Rascado, J. L., Ilic, L., Kokkalis, P., Maurizi, A., Mona, L., Monti, F., Muñoz-Porcar, C., Nicolae, D., Papayannis, A., Pappalardo, G., Pejanovic, G., Pereira, S. N., Perrone, M. R., Pietruczuk, A., Posyniak, M., Rocadenbosch, F., Rodríguez-Gómez, A., Sicard, M., Siomos, N., Szkop, A., Terradellas, E., Tsekeri, A., Vukovic, A., Wandinger, U., and Wagner, J.: A methodology for investigating dust model performance using synergistic EARLINET/AERONET dust concentration retrievals, Atmos. Meas. Tech., 8, 3577-3600, doi:10.5194/amt-83577-2015, 2015.

Bösenberg, J. and Hoff, R. M.: Plan for the implementation of the GAW Aerosol Lidar Observation Network GALION, World Meteorological Report \#178, WMO Geneva, Switzerland, 2007.

Bösenberg, J., Ansmann, A., Baldasano, J. M., Balis, D., Böckmann, Ch., Calpini, B., Chaikovsky, A., Flamant, P., Hågård, A., Mitev, V., Papayannis, A., Pelon, J., Resendes, D., Schneider J., Spinelli, N., Trickl, T., Vaughan, G., Visconti, G., and Wiegner, M.: EARLINET-A European Aerosol Research Lidar Network, Advances in Laser Remote sensing, in: Selected papers 20th Int. Laser Radar Conference (ILRC), 10-14 July 2000, Vichy, France, 155-158, 2000.

Cattrall, C., Reagan, J., Thome, K., and Dubovik, O.: Variability of aerosol and spectral lidar and extinction ratios of key aerosol types derived from selected aerosol robotic network locations, J. Geophys. Res, 110, D10S11, doi:10.1029/2004JD005124, 2005.

Chaikovsky, A., Bril, A., Barun, V., Dubovik, O., Holben, B., Goloub, P., and Sobolewski, P.: Methodology and sample results of retrieving aerosol parameters by combined multi-wavelength lidar and Sun-sky scanning measurements, Proc. SPIE 5397, Tenth Joint International Symposium on Atmospheric and Ocean Optics/Atmospheric Physics. Part II: Laser Sensing and Atmospheric Physics, 23 February 2004, 146, doi:10.1117/12.548588, 2004a.

Chaikovsky, A., Bril, A., Barun, V., Dubovik, O., Holben, B., Thompson, A., Goloub, P., and Sobolewski P.: Studying altitude profiles of atmospheric aerosol parameters by combined multiwavelength lidar and sun sky radiance measurements, Reviewed and Revised papers presented at the 22nd International Laser Radar Conference (ILRC 2004), 12-16 July 2004, Matera, Italy, 345-348, 2004b.

Chaikovsky, A., Bril, A., Dubovik, O., Holben, B., Thompson, A., Goloub, P., O’Neill, N., Sobolewski, P., Bösenberg, J., Ansmann, A., Wandinger, U., and Mattis, I.: CIMEL and multiwavelength lidar measurements for troposphere aerosol altitude distributions investigation, long-range transfer monitoring and regional ecological problems solution: field validation of retrieval techniques, Optica Pura y Aplicada, 37, 3241-3246, 2004c.

Chaikovsky, A., Kabashnikov, V., Germenchuk, M., Goloub, P., Dubovik, O., Zhukova, O., Ivanov, A., Kozeruk, B., Korol, Y., Lopatsin, A., Asipenka, F., and Utochkina, S.: Monitoring of transboundary pollution transfer in the atmosphere with use of remote sounding systems and the global and regional measuring network data: I Operational monitoring of particular matter in Belarus region, Nature Resour., 1, 95-108, 2010a (in Russian).

Chaikovsky A., Dubovik, O., Goloub, P., Tanré, D., Lopatsin, A., Denisov, S., Lapyonok, T., and Karol, Y.: The retrieval of aerosol microphysical properties in the vertical column using combined 
lidar/photometer data: a step to integrating photometer and lidar networks, Proceedings of the 25th International Laser Radar Conference, 5-9 July 2010, St.-Petersburg, Russia, 1087-1091. 2010b.

Chaikovsky, A., Dubovik, O., Goloub, P., Tanré, D., Pappalardo, G., Wandinger, U., Chaikovskaya, L., Denisov, S., Grudo, Y., Lopatsin, A., Karol, Y., Lapyonok, T., Korol, M., Osipenko, F., Savitski, D., Slesar, A., Apituley, A., Arboledas, L. A., Binietoglou, I., Kokkalis, P., Granados-Muñoz, M. J., Papayannis, A., Perrone, M. R., Pietruczuk, A., Pisani, G., Rocadenbosch, F., Sicard, M., De Tomasi, F., Wagner, J., and Wang, X.: Algorithm and software for the retrieval of vertical aerosol properties using combined lidar/ radiometer data: Dissemination in EARLINET, in: Proceedings of the 26th International Laser and Radar Conference, 25-29 June 2012, Porto Heli, Greece, 399-402, 2012.

Chaikovsky, A. P., Dubovik, O., Holben, B. N., and Bril A. I.: Methodology to retrieve atmospheric aerosol parameters by combining ground-based measurements of multiwavelength lidar and sun sky-scanning radiometer, Eighth International Symposium on Atmospheric and Ocean Optics: Atmospheric Physics, 28 February 2002, Proc. SPIE 4678, 257-268, doi:10.1117/12.458450, 2002.

Chaikovsky, A. P., Ivanov, A. P., Balin, Y. S., Elnikov, A. V., Tulinov, G. F., Plusnin, I. I., Bukin, O. A., and Chen B. B.: CISLiNet lidar network for monitoring aerosol and ozone: methodology and instrumentation, Atmos. and Oceanic Opt., 18, 958-963, 2005.

Chaykovskii, A. P.: Method for investigating the structure of the stratospheric aerosol layer based on laser echo depolarization measurements, Atmos. and Oceanic Opt., 3, 1221-1223, 1990.

Colarco, P. R., Schoeberl, M. R., Doddridge B. G., Marufu, L. T., Torres O., and Welton, E. J.: Transport of smoke from Canadian forest fires to the surface near Washington, D.C.: Injection height, entrainment, and optical properties, J. Geophys. Res., 109, D06203, doi:10.1029/2003JD004248, 2004.

Committee on Space Research: NASA National Space Science Data Center: COSPAR International Reference Atmosphere (CIRA86): Global Climatology of Atmospheric Parameters. NCAS British Atmospheric Data Centre, available at: http://browse. ceda.ac.uk/browse/badc/cira/data/ (last access: 13 March 2016), 2006.

Cuesta, J., Flamant, H. P., and Flamant, C.: Synergetic technique combining elastic backscatter lidar data and sunphotometer AERONET inversion for retrieval by layer of aerosol optical and microphysical properties, Appl. Optics, 47, 4598-4611, 2008.

David, G., Thomas, B., Nousiainen, T., Miffre, A., and Rairoux, P.: Retrieving simulated volcanic, desert dust and sea-salt particle properties from two/three-component particle mixtures using UV-VIS polarization lidar and T matrix, Atmos. Chem. Phys., 13, 6757-6776, doi:10.5194/acp-13-6757-2013, 2013.

Doicu, A., Trautmann T., and Schreier, F. Numerical Regularization for Atmospheric Inverse Problem, Springer-Verlag, BerlinHeidelberg, Germany, 426 pp., 2010.

Dubovik, O. and King, M.: A flexible inversion algorithm for retrieval of aerosol optical properties from Sun and sky radiance measurements, J. Geophys. Res., 105, 20673-20696, 2000.

Dubovik, O., Smirnov, A., Holben, B. N., King, M. D., Kaufman, Y., Eck T. F., and Slutsker, I.: Accuracy assessments of aerosol optical properties retrieved from Aerosol Robotic Network (AERONET) sun and sky radiance measurements, J. Geophys. Res., 105, 9791-9800, 2000.

Dubovik, O., Holben, B. N., Lapyonok, T., Sinyuk, A., Mishchenko, M. I., Yang, P., and Slutsker, I.: Non-spherical aerosol retrieval method employing light scattering by spheroids, Geophys. Res. Lett., 29, 54-1-54-4, doi:10.1029/2001GL014506, 2002.

Dubovik, O.: Optimization of Numerical Inversion in Photopolarimetric Remote Sensing, in: Photopolarimetry in Remote Sensing, edited by: Videen, G., Yatskiv, Y., and Mishchenko, M., Kluwer Academic Publishers, Dordrecht, the Netherlands, 65106, 2004.

Dubovik, O., Sinyuk, A., Lapyonok, T., Holben, B. N., Mishchenko, M., Yang, P., Eck, T. F., Volten, H., Munoz, O., Veihelmann, B., van der Zande, W. J., Leon, J.-F., Sorokin, M., and Slutsker, I.: Application of spheroid models to account for aerosol particle nonsphericity in remote sensing of desert dust, J. Geophys. Res., 111, D11208, doi:10.1029/2005JD006619, 2006.

Dubovik, O., Herman, M., Holdak, A., Lapyonok, T., Tanré, D., Deuzé, J. L., Ducos, F., Sinyuk, A., and Lopatin, A.: Statistically optimized inversion algorithm for enhanced retrieval of aerosol properties from spectral multi-angle polarimetric satellite observations, Atmos. Meas. Tech., 4, 975-1018, doi:10.5194/amt-4975-2011, 2011.

Dubovik, O., Lapyonok, T., Litvinov, P., Herman, M., Fuertes, D., Ducos, F., Lopatin, A., Chaikovsky, A., Torres, B., Derimian, Y., Xin Huang, Aspetsberger, M., and Federspiel, C.: GRASP: a versatile algorithm for characterizing the atmosphere, SPIE Newsroom, doi:10.1117/2.1201408.005558, 2014.

Fleming, E., Chandra, S., Shoeberl, M., and Barnett, J.: Monthly Mean Global Climatology of Temperature, Wind, Geopotential Height, and Pressure for 0-120 km, NASA Technical Memorandum 100697, 91 pp., 1988.

Freudenthaler, V., Gross, S., Engelmann, R., Mattis, I, Wandinger, U., Pappalardo, G., Amodeo, A., Giunta, A., D’Amico, G., Chaikovsky A., Osipenko, F., Slesar, A., Nicolae, D., Belegante, L., Talianu, C., Serikov, I., Linne, H., Jansen, F., Wilson, K., Graaf, M., Apituley, A., Trickl, T., Giehl, H., and Adam, M.: EARLI09 - Direct intercomparison of eleven EARLINET lidar systems, Proceedings of the 25th International Laser Radar Conference, 5-9 July 2010, St.-Petersburg, Russia, 891-894, 2010.

Ganguly, D., Ginoux, P., Ramaswamy, V., Dubovik, O., Welton, J., Reid, E. A., and Holben, B. N.: Inferring the composition and concentration of aerosols by combining AERONET and MPLNET data: Comparison with other measurements and utilization to evaluate GCM output, J. Geophys. Res., 114, D16203, doi:10.1029/2009JD011895, 2009a.

Ganguly, D., Ginoux, P., Ramaswamy, V., Ganguly, D., Winker, D. M., Holben, B. N., and Tripathi, S. N.: Retrieving the composition and concentration of aerosols over the Indo-Gangetic basin using CALIOP and AERONET data, Geophys. Res. Lett., 36, L13806, doi:10.1029/2009GL038315, 2009b.

Gasteiger, J., Groß, S., Freudenthaler, V., and Wiegner, M.: Volcanic ash from Iceland over Munich: mass concentration retrieved from ground-based remote sensing measurements, Atmos. Chem. Phys., 11, 2209-2223, doi:10.5194/acp-11-22092011, 2011.

Granados-Muñoz, M. J., Guerrero-Rascado, J. L., Bravo-Aranda, J. A., Navas-Guzmán, F., Valenzuela, A., Lyamani, H., Chaikovsky, 
A., Wandinger, U., Ansmann, A., Dubovik, O., Grudo, J., and Alados-Arboledas, L.: Retrieving aerosol microphysical properties by Lidar-Radiometer Inversion Code (LIRIC) for different aerosol types, J. Geophys. Res., 119, 4836-4858, doi:10.1002/2013JD021116, 2014.

Granados-Muñoz, M. J., Bravo-Aranda, J. A., Baumgardner, D., Guerrero-Rascado, J. L., Pérez-Ramírez, D., Navas-Guzmán, F., Veselovskii, I., Lyamani, H., Valenzuela, A., Olmo, F. J., Titos, G., Andrey, J., Chaikovsky, A., Dubovik, O., Gil-Ojeda, M., and Alados-Arboledas, L.: Study of aerosol microphysical properties profiles retrieved from ground-based remote sensing and aircraft in-situ measurements during a Saharan dust event, Atmos. Meas. Tech. Discuss., 8, 9289-9338, doi:10.5194/amtd-8-9289-2015, 2015a.

Granados-Muñoz, M. J., Navas-Guzmán, F., Guerrero-Rascado, J. L., Bravo-Aranda, J. A., Binietoglou, I., Pereira, S. N., Basart, S., Baldasano, J. M., Belegante, L., Chaikovsky, A., Comerón, A., D’Amico, G., Dubovik, O., Ilic, L., Kokkalis, P., MuñozPorcar, C., Nickovic, S., Nicolae, D., Olmo, F. J., Papayannis, A., Pappalardo, G., Rodríguez, A., Schepanski, K., Sicard, M., Vukovic, A., Wandinger, U., Dulac, F., and Alados-Arboledas, L.: Profiling of aerosol microphysical properties at several EARLINET/AERONET sites during July 2012 ChArMEx/EMEP campaign, Atmos. Chem. Phys. Discuss., 15, 32831-32887, doi:10.5194/acpd-15-32831-2015, 2015b.

Hansen, P. C.: The L-curve and its use in the numerical treatment of inverse problems. Computational Inverse Problems in Electrocardiology, WIT Press, Southampton, UK, 119-142, 2001.

Hashimoto, M., Nakajima, T., Dubovik, O., Campanelli, M., Che, H., Khatri, P., Takamura, T., and Pandithurai, G.: Development of a new data-processing method for SKYNET sky radiometer observations, Atmos. Meas. Tech., 5, 2723-2737, doi:10.5194/amt5-2723-2012, 2012.

Hoff, R., Moshary, F., Ahmed, S., Gross, B., Mc-Cormick, M. P., and Parsiani, H.: Plan for the implementation of the CREST Lidar Network (CLN). CREST Publication Series vol 07, no. 012009, University of Maryland, Baltimore County/City College of New York/Hampton University/Mayaguez University, 2009.

Holben, B. N., Eck, T. F., Slutsker, I., Tanré, D., Buis, J. P., Setzer, A., Vermote, E., Reagan, J. A., Kaufman, Y. J., Nakajima, T., Lavenu, F., I, J., and Smirnov, A.: AERONET - A federated instrument network and data archive for aerosol characterization, Remote Sens. Environ., 66, 1-16, 1998.

Holben, B. N., Eck, T. F., Slutsker, I., Smirnov, A., Sinyuk, A., Schafer, J., Giles, D., and Dubovik, O.: AERONET's Version 2.0 quality assurance criteria, in Remote Sensing of the Atmosphere and Clouds, edited by: Tsay, S.-C., Nakajima, T., Singh, R. P., and Sridharan R., Proc. SPIE, 6408, 64080Q, doi:10.1117/12.706524, 2006.

Kabashnikov, V., Chaikovsky, A., Denisov, S., Dubovik, O., Goloub, P., Ivanov, A., V. Kusmin, V., Kazeruk, D., Korol, M., Karol, Y., Lopatsin, A., Miatselskaya, N., Osipenko, F., Pietruczuk, F., Slesar, A., Sobolewski, H., and Tanre, D.: Long range transport of air pollution in the east European regions: four years observations, in Proceedings of the 25th International Laser Radar Conference, 5-9 July 2010, St.-Petersburg, Russia, 1043 1046, 2010

Klett, D.: Stable analytical inversion solution for processing lidar returns, Appl. Optics, 20, 211-220, 1981.
Kokkalis, P., Papayannis, A., Amiridis, V., Mamouri, R. E., Chaikovsky, A., Dubovik, O., and Tsekeri, A.: Evaluation of fine mode lidar concentration retrievals using airborne in-situ measurements, Reviewed and revised papers of the 26th International Lidar Radar Conference, 25-29 June 2012, Porto Heli, Peloponnesus, Greece, 617-620, 2012.

Kokkalis, P., Papayannis, A., Amiridis, V., Mamouri, R. E., Veselovskii, I., Kolgotin, A., Tsaknakis, G., Kristiansen, N. I., Stohl, A., and Mona, L.: Optical, microphysical, mass and geometrical properties of aged volcanic particles observed over Athens, Greece, during the Eyjafjallajökull eruption in April 2010 through synergy of Raman lidar and sunphotometer measurements, Atmos. Chem. Phys., 13, 9303-9320, doi:10.5194/acp-13-9303-2013, 2013.

Levenberg, K.: A method for the solution of certain problems in least squares, Q. Appl. Math., 2, 164-168, 1944.

Levy, R. C, Remer, L. A., Mattoo, S., Vermote, E. F., and Kaufman, Y. J.: Second-generation operational algorithm: Retrieval of aerosol properties over land from inversion of moderate resolution imaging spectroradiometer spectral reflectance, J. Geophys. Res, 112, D13211, doi:10.1029/2006JD007811, 2007a.

Levy, R. C, Remer, L. A., and Dubovik, O.: Global aerosol optical models and application to Moderate Resolution Imaging Spectroradiometer aerosol retrieval over land, J. Geophys. Res., 112, D13210, doi:10.1029/2006JD007815, 2007b.

Li, Z., Goloub, P., Dubovik, O., Blarel, L., Zhang, W., Podvin, T., Sinyuk A., Sorokin, M., Chen, H., Holben, B. N., Tanre, D., Canini, M., and Buis, J.-P: Improvements for ground-based remote sensing of atmospheric aerosol properties by additional polarimetric measurements, J. Quant. Spectrosc. Ra., 110, 19541961, 2009.

Lopatin, A., Dubovik, O., Chaikovsky, A., Goloub, P., Lapyonok, T., Tanré, D., and Litvinov, P.: Enhancement of aerosol characterization using synergy of lidar and sun-photometer coincident observations: the GARRLiC algorithm, Atmos. Meas. Tech., 6, 2065-2088, doi:10.5194/amt-6-2065-2013, 2013.

Lund Myhre, C., Toledano, C., Myhre, G., Stebel, K., Yttri, K. E., Aaltonen, V., Johnsrud, M., Frioud, M., Cachorro, V., de Frutos, A., Lihavainen, H., Campbell, J. R., Chaikovsky, A. P., Shiobara, M., Welton, E. J., and Tørseth, K.: Regional aerosol optical properties and radiative impact of the extreme smoke event in the European Arctic in spring 2006, Atmos. Chem. Phys., 7, 58995915, doi:10.5194/acp-7-5899-2007, 2007.

Marquardt, D.: An algorithm for least-squares estimation of nonlinear parameters, SIAM J. Appl. Math., 11, 431-441, 1963.

Matthias, V., Bösenberg, J., Freudenthaler, V., Amodeo, A., Balis, D., Chaikovsky, A., Chourdakis, G., Comeron, A., Delaval, A., De Tomasi, F., Eixmann, R., Hågård, A., Komguem, L., Kreipl, S., Matthey, R., Mattis, I., Rizi, V., Rodriguez, J. A., Simeonov, V., and Wang, X.: Aerosol lidar intercomparison in the framework of the EARLINET project. 1. Instruments, Appl. Optics, 43, 961-976, 2004.

McKendry, I., Strawbridge, K., O’Neill, N., Macdonald, A. M., Liu, P., Leaitch, R., Anlauf, K., Jaegle, L., Fairlie, T. D., and Westphal, D.: Trans-Pacific transport of Saharan dust to western North America: A case study, J. Geophys. Res., 112, D01103, doi:10.1029/2006JD007129, 2007.

McKendry, I., Strawbridge, K., Karumudi, M. L., O’Neill, N., Macdonald, A. M., Leaitch, R., Jaffe, D., Cottle, P., Sharma, S., Sheri- 
dan, P., and Ogren, J.: Californian forest fire plumes over Southwestern British Columbia: lidar, sunphotometry, and mountaintop chemistry observations, Atmos. Chem. Phys., 11, 465-477, doi:10.5194/acp-11-465-2011, 2011.

Mishchenko, M. I., Hovenier, J. W., and Travis, L. D.: Light Scattering by Nonspherical Particles, Elsevier, New York, USA, 2000.

Mishchenko, M. I., Travis, L. D., and Lacis, A. A.: Scattering, Absorption, and Emission of Light by Small Particles, Cambridge Univ. Press, New York, USA, 2002.

Müller, D., Mattis, I., Wandinger, U., Ansmann, A., Althausen, D., Dubovik, O., Eckhardt, S., and Stohl, A.: Saharan dust over a Central European EARLINET-AERONET site: Combined observations with Raman lidar and Sun photometer, J. Geophys. Res., 108, 4345, doi:10.1029/2002JD002918, 2003.

Müller, D., Veselovskii, I., Kolgotin, A., Tesche, M., Ansmann, A., and Dubovik, O.: Vertical profiles of pure dust and mixed smoke-dust plumes inferred from inversion of multiwavelength Raman/polarization lidar data and comparison to AERONET retrievals and in situ observations, Appl. Optics, 52, 3178-3202 doi:10.1364/AO.52.003178, 2013.

Murayama, T., Sugimoto, N., Matsui, I., Liu, Z., Sakai, T., Shibata, T., Iwsasaka, Y., Won, J.-G., Yoon, S.-C., Li, T., Zhou, J., and Hu, H.: Lidar Network Observation of Asian Dust, in: Advances in Laser Remote sensing, Selected papers 20th Int. Laser Radar Conference (ILRC), 10-14 July 2000, Vichy, France, edited by: Dabas, A., Loth, C., and Pelon, J., 169-177, 2001.

Nemuc, A., Vasilescu, J., Talianu, C., Belegante, L., and Nicolae, D.: Assessment of aerosol's mass concentrations from measured linear particle depolarization ratio (vertically resolved) and simulations, Atmos. Meas. Tech., 6, 3243-3255, doi:10.5194/amt-63243-2013, 2013.

Papayannis, A., Amiridis, V., Mona, L., Tsaknakis, G., Balis, D., Bosenberg, J., Chaikovski, A., De Tomasi, F., Grigorov, I., Mattis, I., Mitev, V., Muller, D., Nickovic, S., Perez, C., Pietruczuk, A., Pisani, G., Ravetta, F., Rizi, V., Sicard, M., Trickl, T., Wiegner, M., Gerding, M., Mamouri, R. E., D’Amico, G., and Pappalardo, G.: Systematic lidar observations of Saharan dust over Europe in the frame of EARLINET (2000-2002), J. Geophys. Res., 113, D10204, doi:10.1029/2007JD009028, 2008.

Papayannis, A., Mamouri, R. E., Amiridis, V., Giannakaki, E., Veselovskii, I., Kokkalis, P., Tsaknakis, G., Balis, D., Kristiansen, N. I., Stohl, A., Korenskiy, M., Allakhverdiev, K., Huseyinoglu, M. F., and Baykara, T.: Optical properties and vertical extension of aged ash layers over the Eastern Mediterranean as observed by Raman lidars during the Eyjafjallajokull eruption in May 2010, Atmos. Environ., 48, 56-65, 2012.

Papayannis, A., Nicolae, D., Kokkalis, P., Binetoglou, I., Talianu, C., Belegante, L., Tsaknakis., G., Cazacu, M. M., Vetres, I., and Ilic, I.: Optical, size and mass properties of mixed type aerosols in Greece and Romania as observed by synergy of lidar and sunphotometers in combination with model simulations: A case study, Sci. Tot. Environ., 500-501, 277-294, 2014.

Pappalardo, G., Amodeo, A., Apituley, A., Comeron, A., Freudenthaler, V., Linné, H., Ansmann, A., Bösenberg, J., D’Amico, G., Mattis, I., Mona, L., Wandinger, U., Amiridis, V., AladosArboledas, L., Nicolae, D., and Wiegner, M.: EARLINET: towards an advanced sustainable European aerosol lidar network, Atmos. Meas. Tech., 7, 2389-2409, doi:10.5194/amt-7-23892014, 2014.
Pietruczuk, A. and Chaikovsky, A. P.: Properties of fire smoke in eastern Europe measured by remote sensing methods, Proceedings of SPIE, 6745, 67451T, doi:10.1117/12.740916, 2007.

Rodgers C. D.: Inverse methods for atmospheric sounding. Theory and Practice. Word Scientific, Singapore, 238 pp., 2000.

Russell, P. B., Swissler, T. J., and McCormick, M. P.: Methodology for error analysis and simulation of lidar aerosol measurements, Appl. Optics, 18, 3783-3797, 1979.

Schuster, G. L., Vaughan, M., MacDonnell, D., Su, W., Winker, D., Dubovik, O., Lapyonok, T., and Trepte, C.: Comparison of CALIPSO aerosol optical depth retrievals to AERONET measurements, and a climatology for the lidar ratio of dust, Atmos. Chem. Phys., 12, 7431-7452, doi:10.5194/acp-12-7431-2012, 2012.

Slesar, A. S., Chaykovskii, A. P., Ivanov, A. P., Denisov, S. V., Korol, M. M., Osipenko, F. P., Balin, Yu. S., Kokhanenko, G. P., and Penner I. E.: Fotodetector modules for CIS-LiNet lidar network stations, Atmos. and Oceanic Opt., 26, 1073-1081, 2013 (in Russian).

Slesar, A. S., Chaikovskii, A. P., Denisov, S. V., Korol, M. M., Osipenko, F. P., Balin, Yu. S., Kokhanenko, G. P., Penner, I. E., and Novoselov M. M.: Development of photodetectors for recording lidar signals in the photon counting and analog modes, Proc. SPIE 9680, 21st International Symposium Atmospheric and Ocean Optics: Atmospheric Physics, 19 November 2015, 96802Q, doi:10.1117/12.2203666, 2015.

Takamura, T., Nakajima, T., and SKYNET community group: Overview of SKYNET and its activities, Optica Pura y Aplicada, 37, 3303-3308, 2004.

Tarantola, A.: Inverse Problem Theory: Methods for Data Fitting and Model Parameter Estimation, Elsevier, Amsterdam, the Netherlands, 614 pp., 1987.

Tesche, M., Ansmann, A., Müller, D., Althausen, D., Engelmann, R., Freudenthaler, V., and Groß, S.: Separation of dust and smoke profiles over Cape Verde by using multiwavelength Raman and polarization lidars during SAMUM 2008, J. Geophys. Res., 114, D13202, doi:10.1029/2009JD011862, 2009.

Tikhonov, A. N. and Arsenin, V. Y.: Solution of Ill-Posed Problems, Wiley, New York, USA, 300 pp., 1977.

Trefethen, L. N. and Bau, D.: Numerical Linear Algebra, SIAM, Philadelphia, USA, 361 pp., 1997.

Tsekeri, A., Amiridis, V., Kokkalis, P., Basart, S., Chaikovsky, A., Dubovik, O., Mamouri, R. E., Baldasano, J. M., and Papayannis, A.: Evaluation of dust modelling using a synergetic algorithm of lidar and sunphotometer data. Reviewed and Revised papers of the 26th International Lidar Radar Conference, 25-29 June 2012, Porto Heli, Peloponnesus, Greece, 621-624, 2012.

Tsekeri, A., Amiridis, V., Kokkalis, P., Basart, S., Chaikovsky, A., Dubovik, O., Mamouri, R. E., Papayannis, A., and Baldasano, J. M.: Application of a Synergetic Lidar and Sunphotometer Algorithm for the Characterization of a Dust Event Over Athens, Greece, British J. of Environment and Climate Change, 3, 531546, doi:10.9734/BJECC/2013/2615, 2013.

Turchin, V. F., Kozlov, V. P., and Malkevich, M. S.: The use of mathematical-statistics methods in the solution of incorrectly posed problems, Sov. Phys. Uspekhi, 13, 681-703, 1971.

Twomey, S.: Introduction to the mathematics of inversion in remote sensing and indirect measurements, Elsevier, Amsterdam, the Netherlands, 1977. 
Veselovskii, I, Kolgotin, A., Müller, D., and Whiteman, D.: Information content of multiwavelength lidar data with respect to microphysical particle properties derived from eigenvalue analysis, Appl. Optics, 44, 5292-5303, 2005.

Veselovskii, I., Dubovik, O., Kolgotin, A., Lapyonok ,T., Di Girolamo, P., Summa, D., Whiteman, D. N., Mishchenko, M., and Tanre D.: Application of randomly oriented spheroids for retrieval of dust particle parameters from multiwavelength lidar measurements. J. Geophys. Res., 115, D21203, doi:10.1029/2010JD014139, 2010.

Vogel, C. R.: Computational Methods for Inverse Problems, SIAM, Philadelphia, PA, USA, 183 pp., 2002.

Volten, H., Muñoz, O., Rol, E., de Haan, J. F., Vassen, W., Hovenier, J. W., Muinonen, K., and Nousiainen, T.: Scattering matrices of mineral particles at $441.6 \mathrm{~nm}$ and $632.8 \mathrm{~nm}$., J. Geophys. Res., 106, 17375-17401, 2001.

Wagner, J., Ansmann, A., Wandinger, U., Seifert, P., Schwarz, A., Tesche, M., Chaikovsky, A., and Dubovik, O.: Evaluation of the Lidar/Radiometer Inversion Code (LIRIC) to determine microphysical properties of volcanic and desert dust, Atmos. Meas. Tech., 6, 1707-1724, doi:10.5194/amt-6-1707-2013, 2013.

Wandinger, U., Freudenthaler, V., Baars, H., Amodeo, A., Engelmann, R., Mattis, I., Groß, S., Pappalardo, G., Giunta, A., D’Amico, G., Chaikovsky, A., Osipenko, F., Slesar, A., Nicolae, D., Belegante, L., Talianu, C., Serikov, I., Linné, H., Jansen, F., Apituley, A., Wilson, K. M., de Graaf, M., Trickl, T., Giehl, H., Adam, M., Comerón, A., Muñoz, C., Rocadenbosch, F., Sicard, M., Tomás, S., Lange, D., Kumar, D., Pujadas, M., Molero, F., Fernández, A. J., Alados-Arboledas, L., Bravo-Aranda, J. A., Navas-Guzmán, F., Guerrero-Rascado, J. L., Granados-Muñoz, M. J., Preißler, J., Wagner, F., Gausa, M., Grigorov, I., Stoyanov, D., Iarlori, M., Rizi, V., Spinelli, N., Boselli, A., Wang, X., Lo Feudo, T., Perrone, M. R., De Tomasi, F., and Burlizzi, P.: EARLINET instrument intercomparison campaigns: overview on strategy and results, Atmos. Meas. Tech. Discuss., 8, 1047310522, doi:10.5194/amtd-8-10473-2015, 2015.
Welton, E. J., Campbell, J. R., Berkoff, T. A., Spinhirne, J. D., Tsay, S.-C., Holben, B., and Shiobara, M.: The Micro-pulse Lidar Network (MPL-Net), in: Lidar Remote Sensing in Atmospheric and Earth Sciences, Reviewed and revised papers at the twenty-first International Laser Radar Conference (ILRC21), 1705 Quebec, Canada, 8-12 July 2002, edited by: Bisonnette, L. R., Roy, G., and Vallée, G., Defence R\&D Canada-Vacartier, 285-288, 2002.

Winker, D. M., Hostetler, C. A., Vaughan, M. A., and Omar, A. H.: CALIOP Algorithm Theoretical Basis Document. Part 1: CALIOP Instrument, and Algorithms Overview, PC-SCI-202, Part 1, Release 2.0, 9 September 2006, 29 pp., 2006. 